\title{
UCRL-CONF-223451
}

\section{Overview of Tabletop X-ray Laser Development at the Lawrence Livermore National Laboratory}

J. Dunn, V. N. Shlyaptsev, J. Nilsen, R. F. Smith, R. Keenan, S. J. Moon, A. J. Nelson, J. R. Hunter, Y. L. Li, A. L. Osterheld, R. Shepherd, J. Filevich, J. J. Rocca, M. C. Marconi, H. Fiedorowicz, A. Bartnik, A. Ya. Faenov, T. A. Pikuz, P. Zeitoun, M. Fajardo, S. Hubert

August 7, 2006

10th International Conference on X-ray Lasers Berlin, Germany

August 21, 2006 through August 25, 2006 
This document was prepared as an account of work sponsored by an agency of the United States Government. Neither the United States Government nor the University of California nor any of their employees, makes any warranty, express or implied, or assumes any legal liability or responsibility for the accuracy, completeness, or usefulness of any information, apparatus, product, or process disclosed, or represents that its use would not infringe privately owned rights. Reference herein to any specific commercial product, process, or service by trade name, trademark, manufacturer, or otherwise, does not necessarily constitute or imply its endorsement, recommendation, or favoring by the United States Government or the University of California. The views and opinions of authors expressed herein do not necessarily state or reflect those of the United States Government or the University of California, and shall not be used for advertising or product endorsement purposes. 


\title{
Overview of Tabletop X-ray Laser Development at the Lawrence Livermore National Laboratory
}

\author{
James Dunn
}

Lawrence Livermore National Laboratory

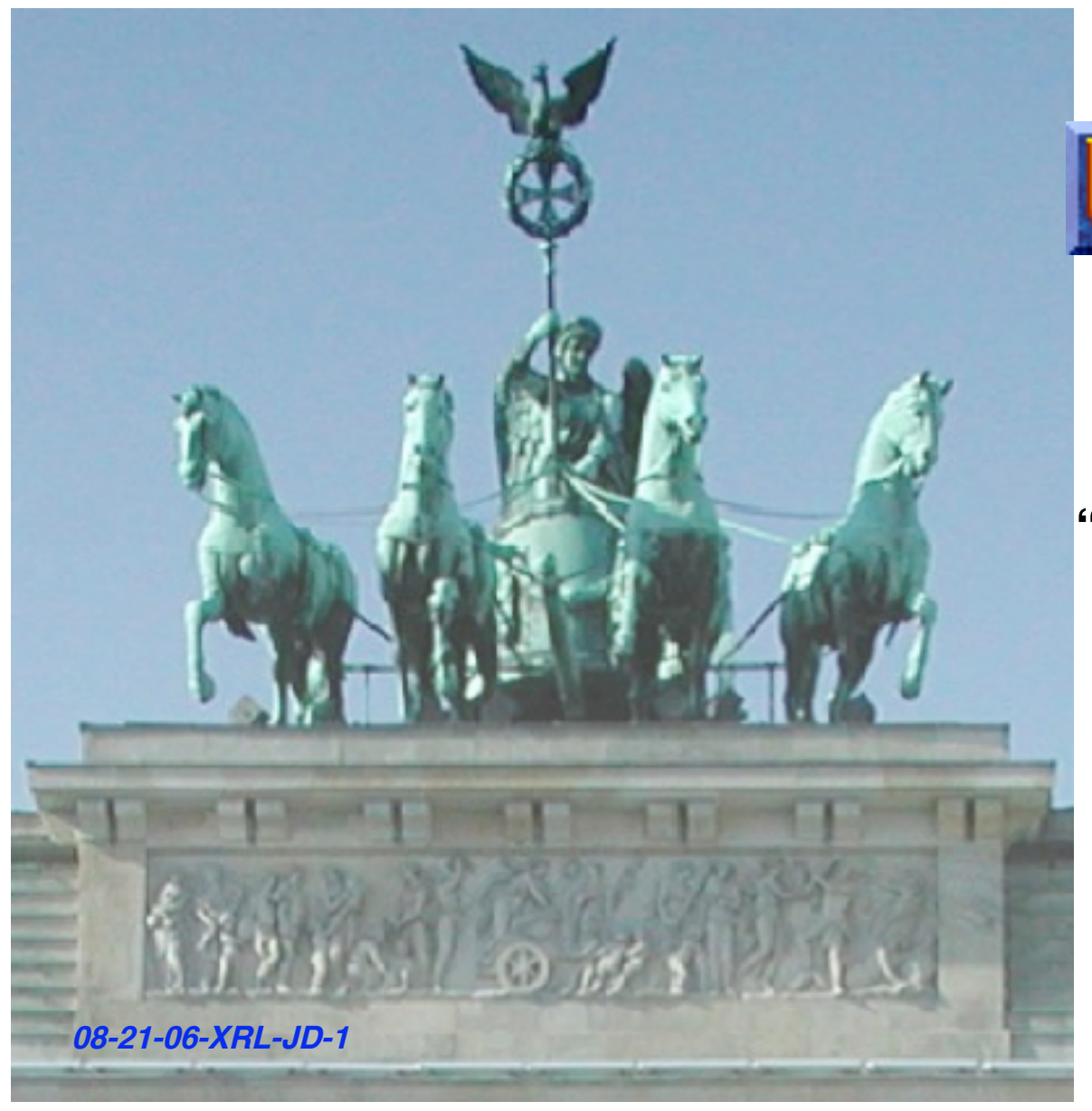

Presented at the:

"10th International Conference on X-ray Lasers"

Berlin, Germany 21 - 25 August, 2006

\author{
UCRL-CONF-Xxxxxx
}

Work performed under the auspices of the US Department of Energy by the University of California Lawrence Livermore National Laboratory under Contract No. W-7405-Eng-48 and in part by US Department of Energy grant No. \#DE-FG52-06NA26152, and in part, by the Ministry of Science and High Education of Poland under grant No 3 T11B 03126 and by the NATO Collaborative Grant PST.CLG.979339. 


\section{Acknowledgment to contributions from many different researchers who participated in experiments:}

V.N. Shlyaptsev

J. Nilsen, R.F. Smith, R. Keenan, S.J. Moon, A.J. Nelson, J.R. Hunter, Y.L. Li ${ }^{*}$,

A.L. Osterheld, R. Shepherd

J. Filevich, J.J. Rocca, M.C. Marconi

H. Fiedorowicz, A. Bartnik

A. Ya. Faenov, T.A. Pikuz

P. Zeitoun, M. Fajardo**

S. Hubert
University of California Davis-Livermore

Lawrence Livermore National Laboratory

NSF ERC for Extreme Ultraviolet Science and Technology and Dept. of Electrical and Computer Engineering, Colorado State University

Institute of Optoelectronics, Military University of Technology,

Multicharged lons Spectra Data Center of VNIIFTRI

Laboratoire d'Optique Appliquée, ENSTA

Commissariat á l'Énergie Atomique

"Present address: Argonne National Laboratory

${ }^{*}$ Present address: Centro de Fisica dos Plasmas, Instituto Superior Técnico 
Overview and Summary:

Give highlights of 10 years (1997 - 2006) of research in Tabletop X-ray Lasers at LLNL

- Initial motivation and background

- Development of laser system

- First Ne-like and Ni-like x-ray laser results

- Generation of saturated output

- Characterization of $x$-ray laser source

- Description of applications at COMET

- Future directions and comments 
X-ray laser experiments circa 1990 with $150 \mathrm{~J}, 1.5$ ns were more challenging, gains were low and required detailed studies

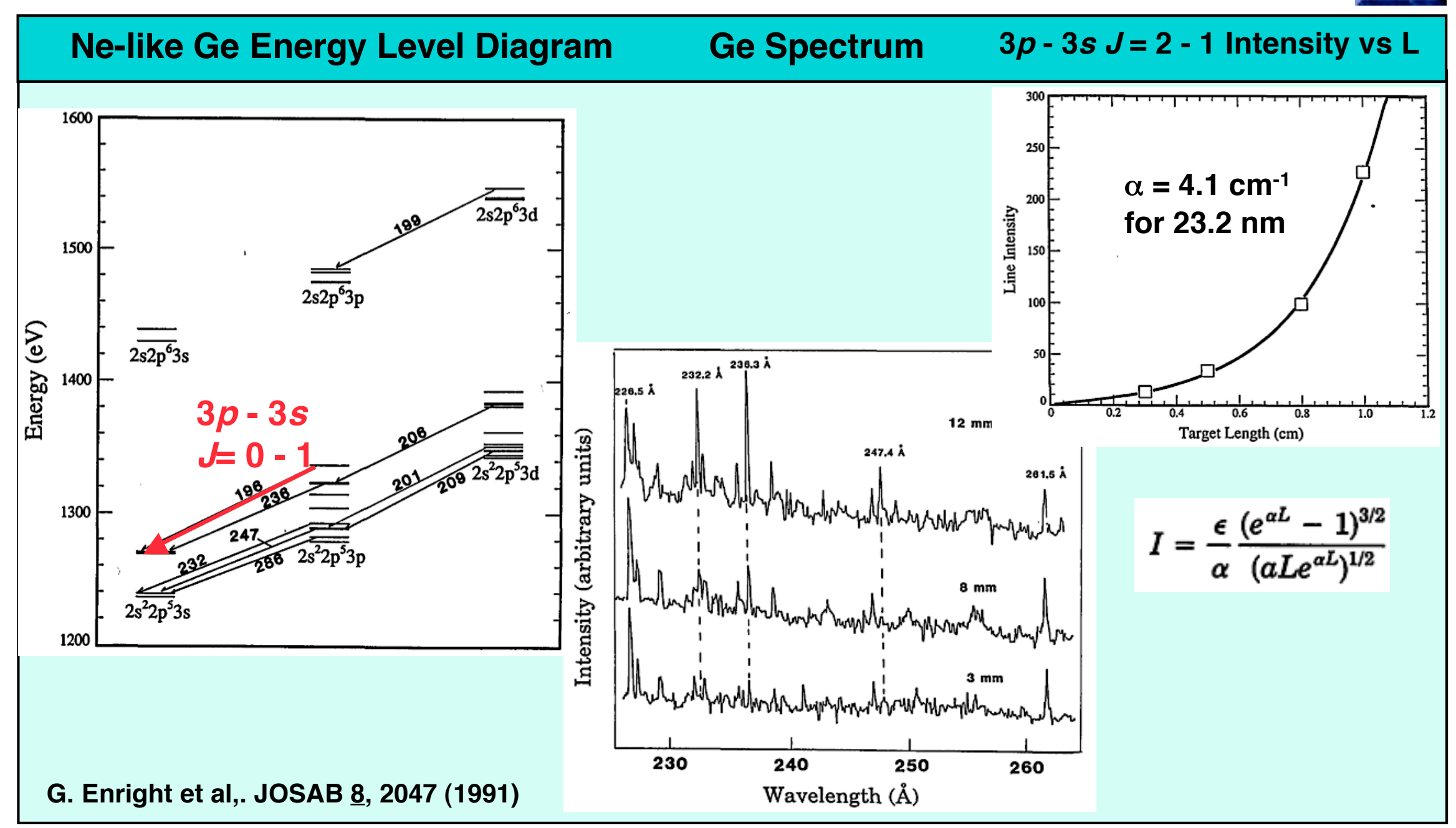

- Before pre-pulse technique developed

- Multiple x-ray lines observed including $3 d-3 p$ line at $19.9 \mathrm{~nm}$ 
Early effort 1984 - 1996 on x-ray lasers was performed on Nova laser at LLNL: collisional excitation scheme was developed

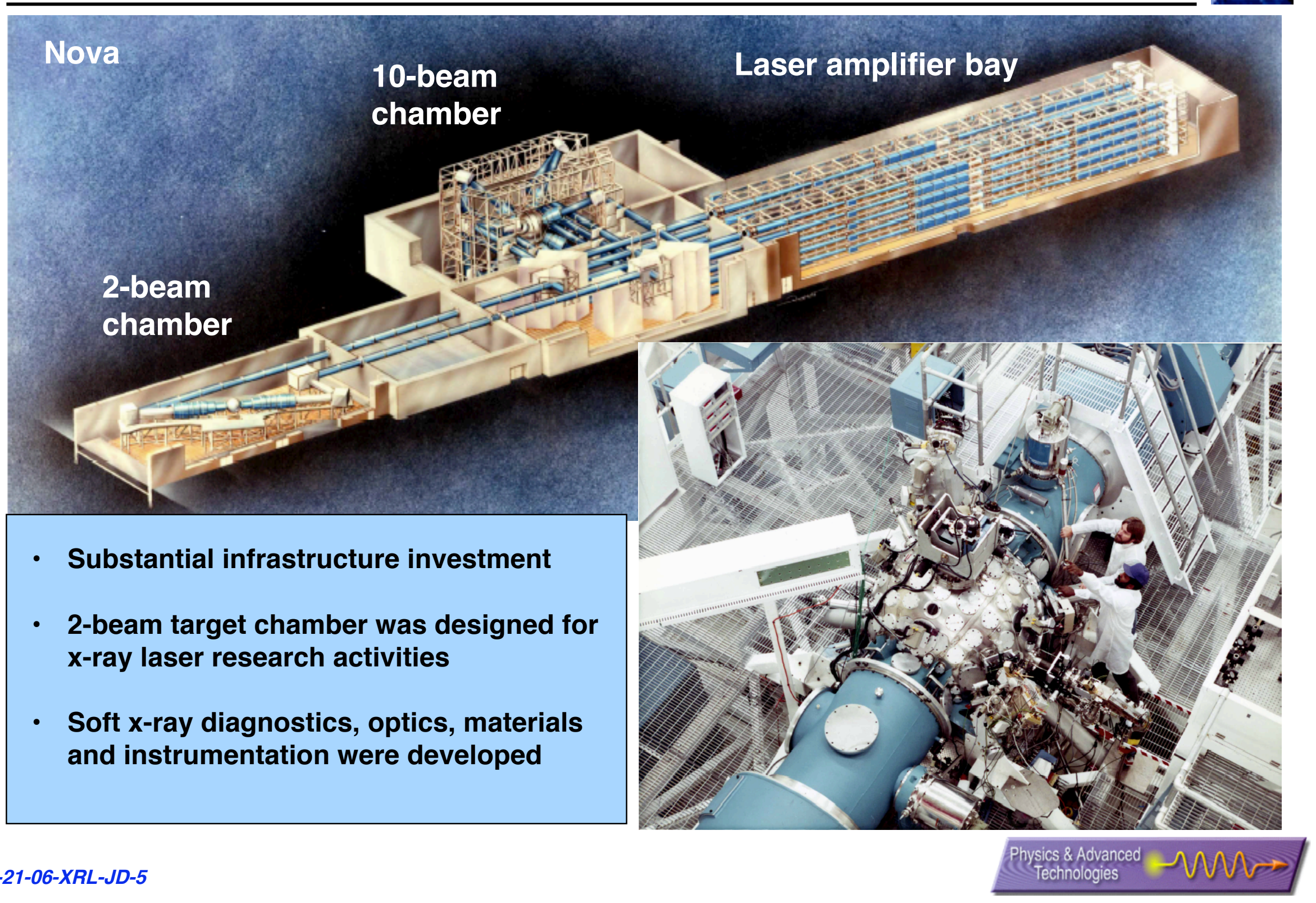


First lasing observed on tabletop system at LLNL for Ne-like $\mathrm{Ti}$ line at $32.5 \mathrm{~nm}$ on 5 June 1997:

- Exponential growth of $\mathbf{g}=24.4 \mathrm{~cm}^{-1}$ inferred from Linford Laser Parameters formula for unsaturated gain for $L=1-5 \mathrm{~mm}$ target lengths Shot $_{\mathrm{Ti}} \mathrm{slab}, \mathrm{L}=10 \mathrm{~mm}$

- XRL output rises rapidly for $L \geq 1 \mathrm{~mm}$ Line Focus $40 \mu \mathrm{m} \times 12.5 \mathrm{~mm}$ Long Pulse: $5.5 \mathrm{~J}, 800 \mathrm{ps}$ (FWHM) Short Pulse: 5.0 J, 1.5 ps (FWHM)

- Estimate $\mathrm{gL}$ product $\sim 15$ for $10 \mathrm{~mm}$ target Laser repetition rate: 1 shot/ $3 \mathrm{~min}$.
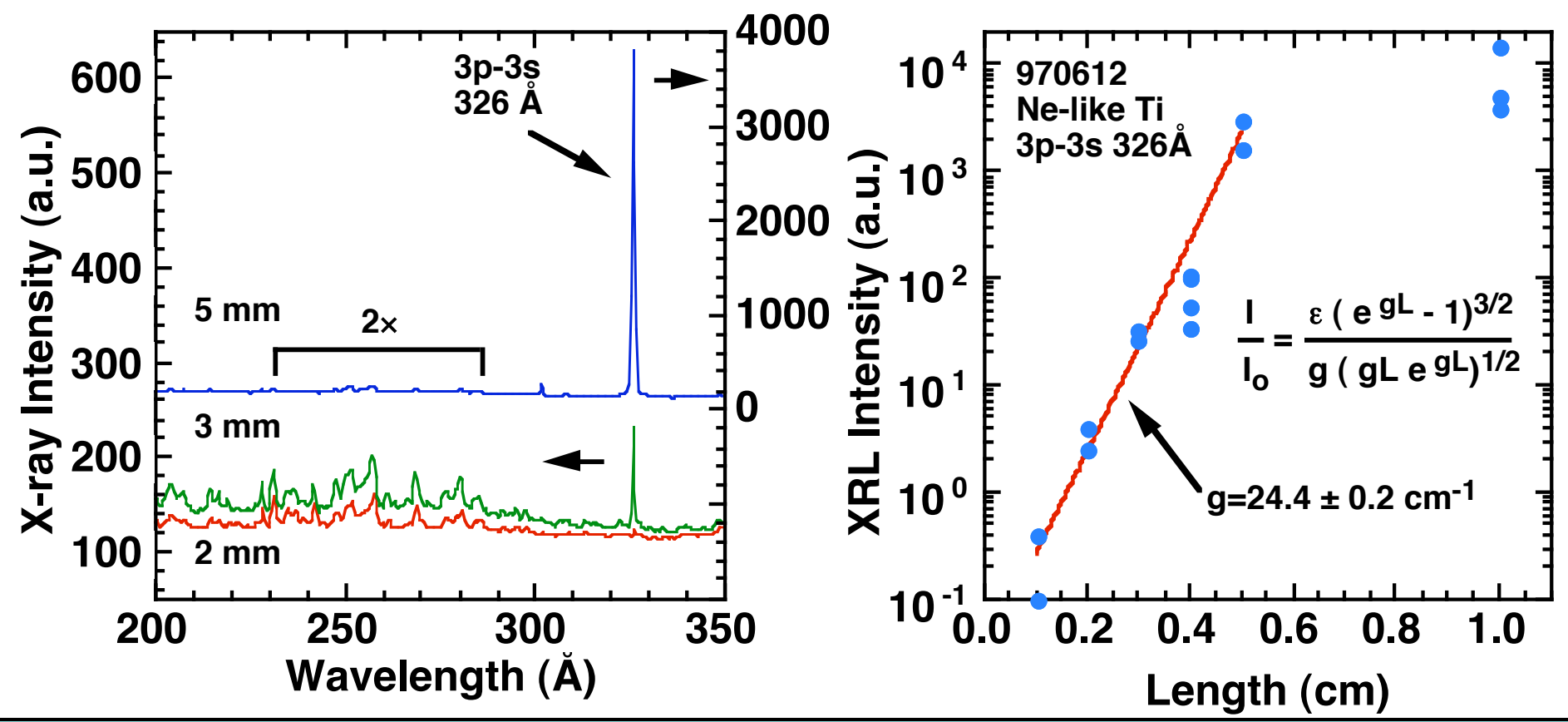

Energy requirements are modest:

$2-3 \mathrm{~J}$ in each beam sufficient to observe XRL 
Ne-like Ti 3p-3s $326 \AA$ A $x$-ray laser line intensity is strongly dependent on short pulse delay

- The arrival of short pulse is delayed relative to the peak of the long pulse to investigate effect on XRL output:

- Observe no XRL line for $\Delta t \leq+800 p s$ and very weak for $\Delta t>2.2$ ns

- Output rises rapidly for delay in window $1.2 \mathrm{~ns}<\Delta \mathrm{t}<2.0 \mathrm{~ns}$ with strong peak at $\sim 1.6 \mathrm{~ns}$
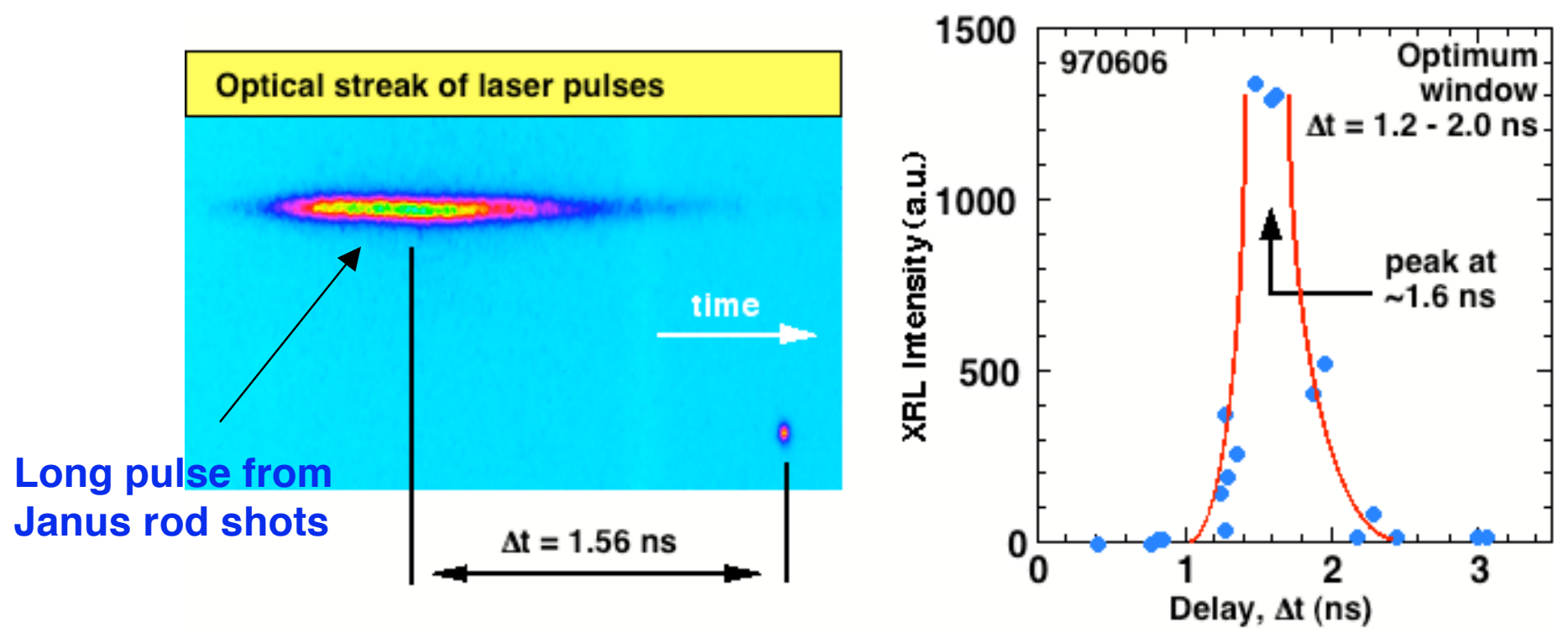


\section{Extrapolate below $150 \AA$ A using transient XRL scheme by studying more efficient $\mathrm{Ni}$-like ion sequence}

- Extend XRL to shorter wavelengths from Ti $326 \AA$ on $3 p-3 s ~ J=0-1$ using higher $Z$ material e.g. Ne-like Fe readily lases at $254.9 \AA$

- Pump intensity requirements ${ }^{1} \mid \sim \mathrm{E}_{\mathrm{XRL}}{ }^{3.5}$ - long pulse laser driver energies $\sim 30 x$ to ionize Ag to Ne-like for $123 \AA$ XRL.

- Need Ni-like 4d-4p J=0-1 scheme to reach $\sim 100 \AA$ and shorter
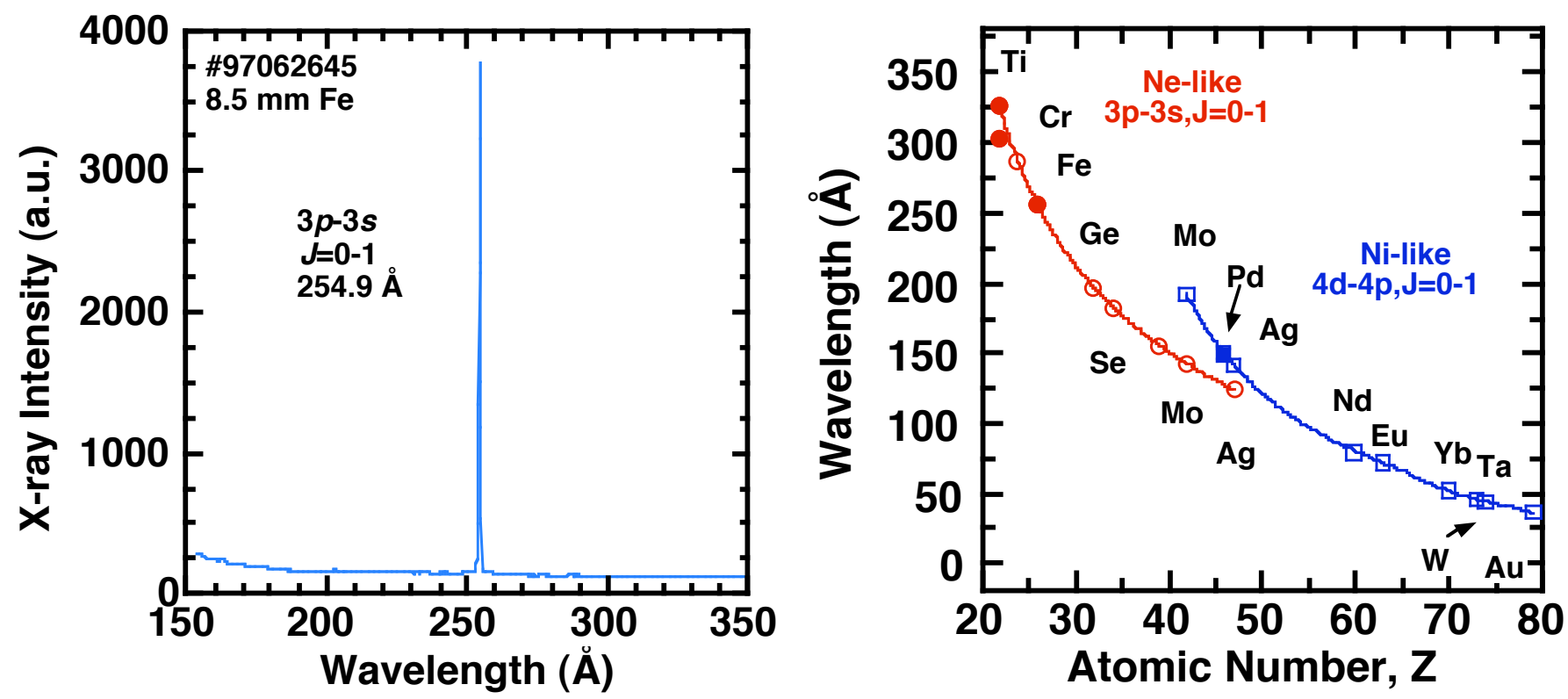

${ }^{1}$ B. MacGowan et al, Phys. Fluids B 4(7), 2326 (1992) 


\section{RADEX simulations indicate high transient gain during and after short pulse for Ni-like Pd $14.7 \mathrm{~nm}$ line}

\section{Experimental conditions simulated: $4.2 \mathrm{~J}, 850 \mathrm{ps}$ pulse, \\ 1.4 ns delay peak-to-peak \\ $5.2 \mathrm{~J}, 1.2 \mathrm{ps}$ pulse \\ Dunn et al, PRL 80, 2825 (1998) $80 \mu \mathrm{m} \times 1 \mathrm{~cm}$ line focus}

\section{RADEX: Maximum Temperature for Ni-like Pd $(Z=46)$}

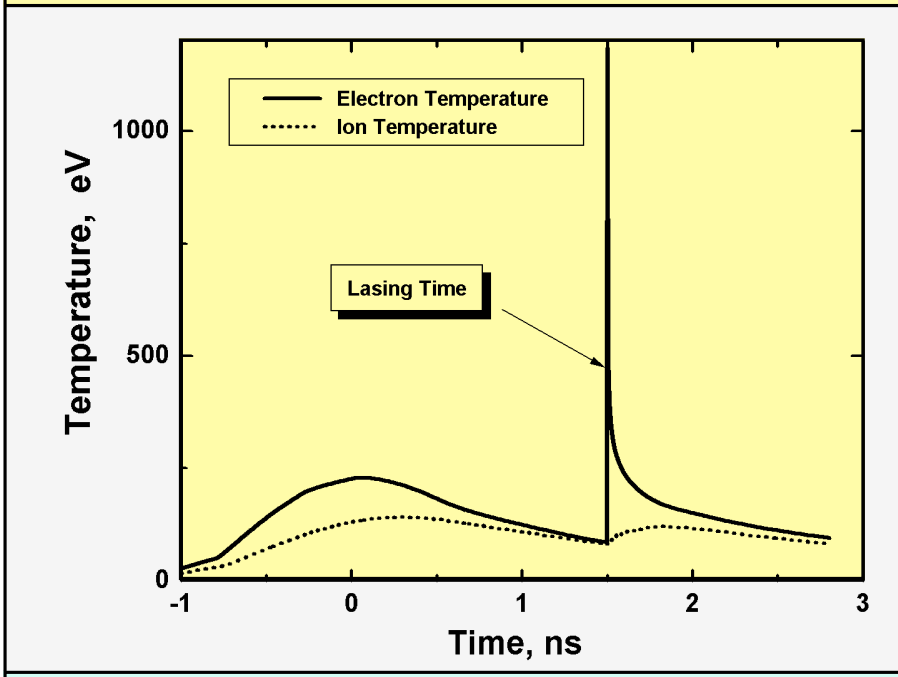

- Plasma cools to $80 \mathrm{eV}$ before arrival of picosecond pulse

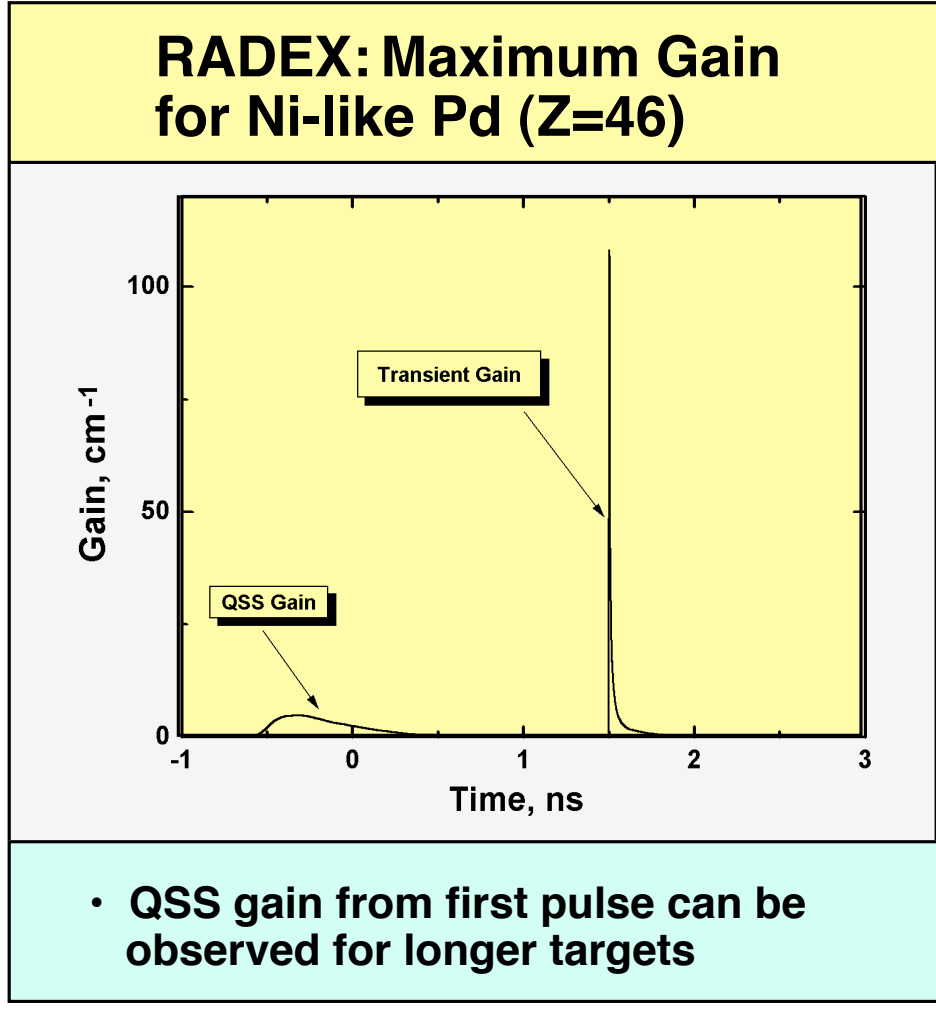

- High gain observed when two laser pulses fired

- Reducing long pulse energy, requires shorter delay 
Moved onto Ni-like Pd 14.7 nm demonstration: X-ray laser exhibits high output for long targets but lower than Ti laser

- Gain measurements made in 2 nd order - reduced gain for longer lengths from finite transit for XRL along plasma column

- High gain $\mathrm{g}>25 \mathrm{~cm}^{-1}$ for $\mathrm{L}=3 \mathrm{~mm}$, overall $\mathrm{gL} \sim 13$
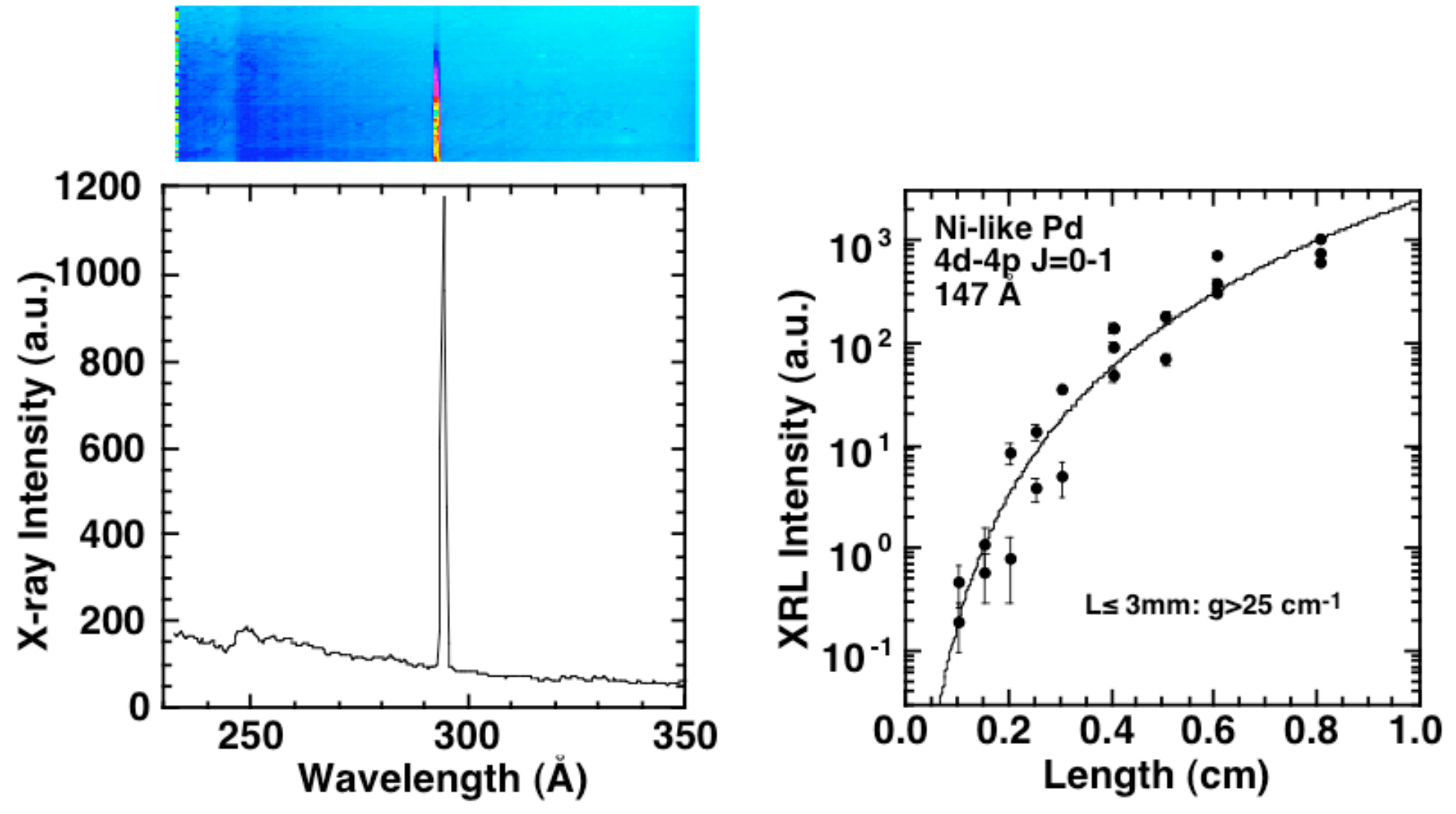


\section{Early 1998: LLNL Table-Top X-ray Laser Facility showing Laser System Schematic}

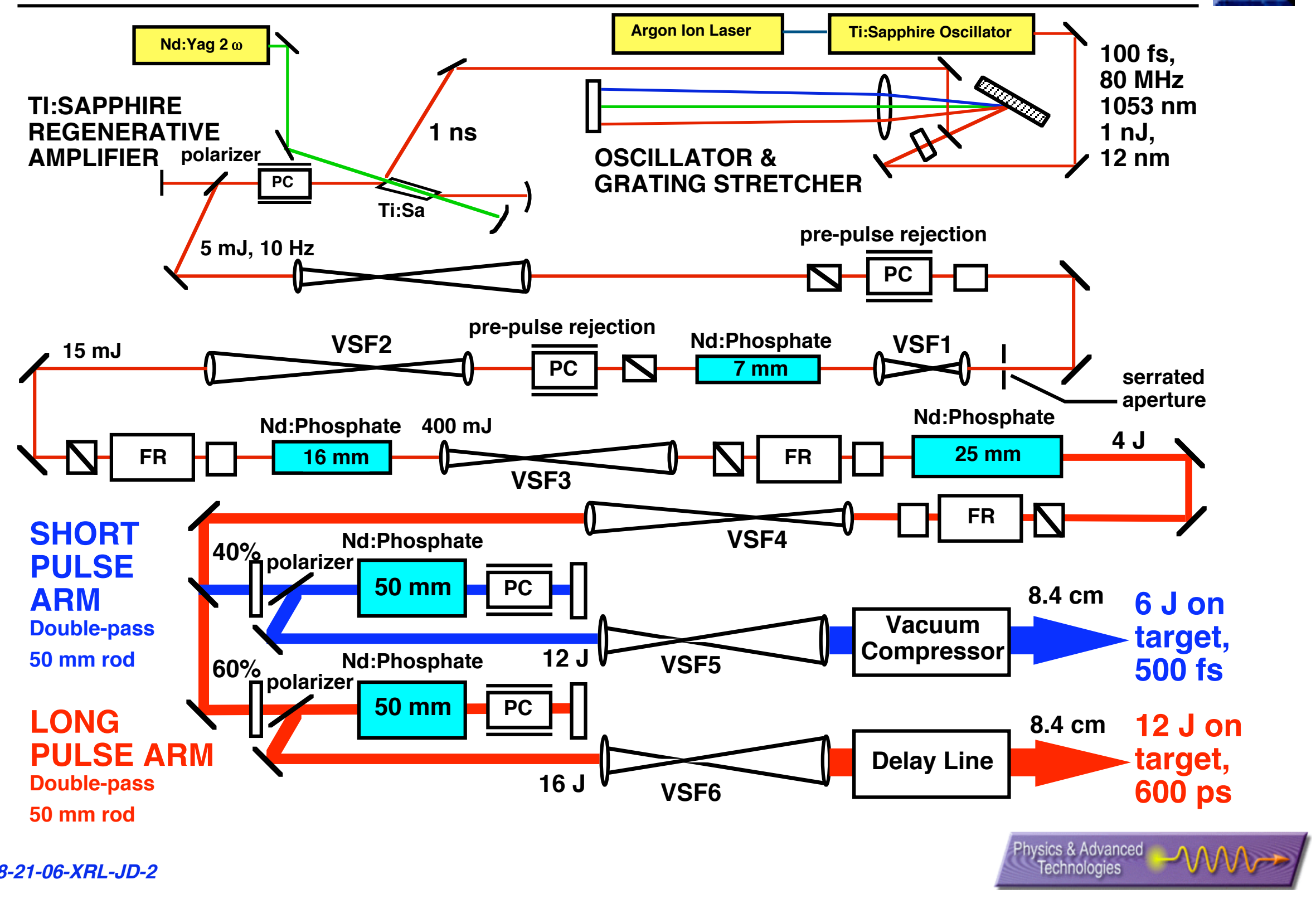




\section{Without traveling wave gain lifetime for Pd follows close to exponential decay with time constant of 8 ps}

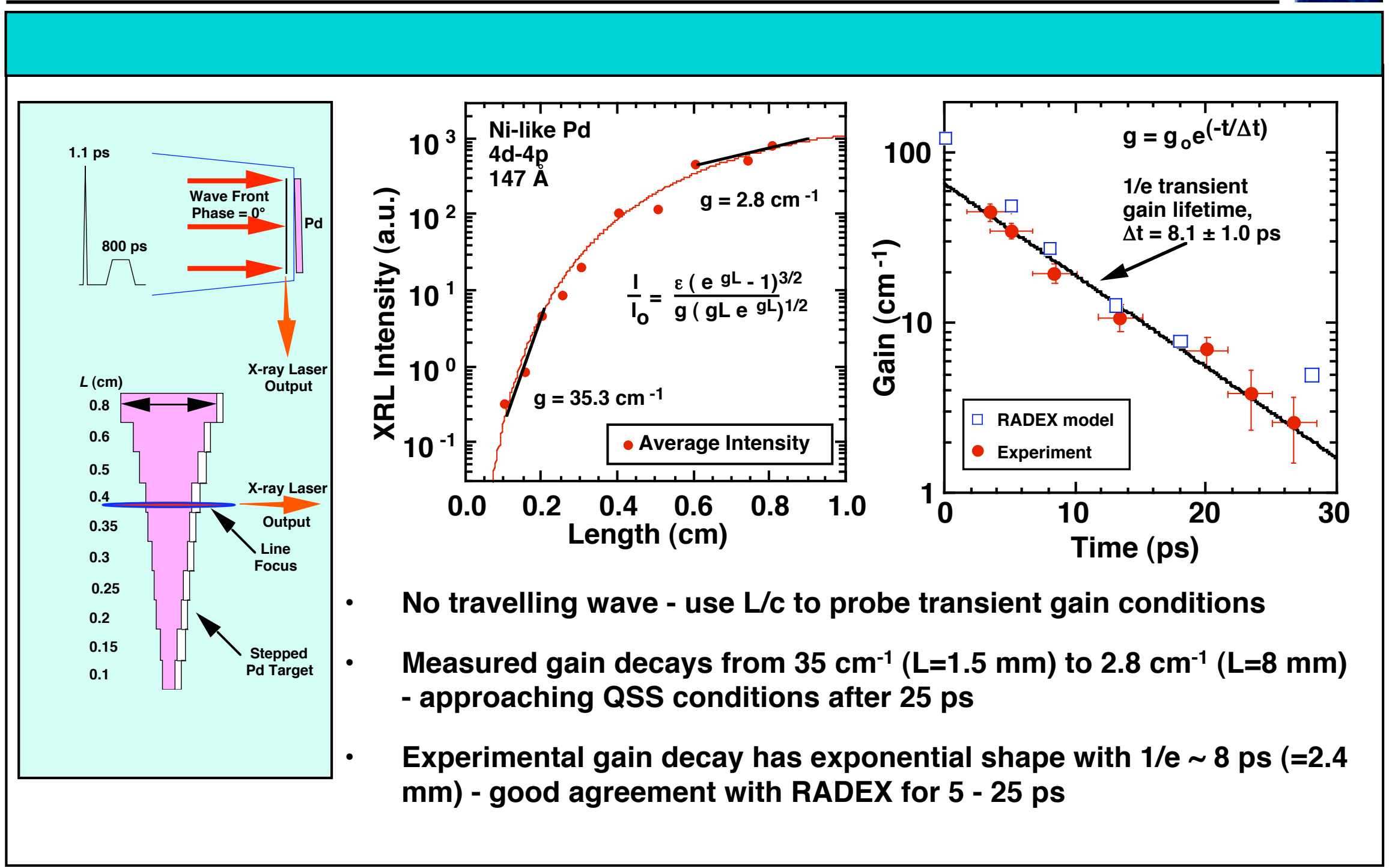




\section{Requirement for atomic spectroscopy to determine Ni-like ion $x$-ray laser lines accurately}

PHYSICAL REVIEW A

VOLUME 58, NUMBER 4

OCTOBER 1998

Wavelengths of the Ni-like $4 d{ }^{1} S_{0}-4 p{ }^{1} P_{1} \mathrm{x}$-ray laser line

PRA 58, R2668 (1998)

Yuelin Li, Joseph Nilsen, James Dunn, and Albert L. Osterheld

Lawrence Livermore National Laboratory, Livermore, California 94550

Alexander Ryabtsev and Sergey Churilov

Institute of Spectroscopy, Troitsk, Moscow Region 142092, Russia

TABLE I. Wavelengths (in $\AA$ ) of the $4 d^{1} S_{0} \rightarrow 4 p^{1} P_{1}$ transition in Ni-like ions with $Z=31-60$. The uncertainties in the last digits are given in parentheses.

\begin{tabular}{|c|c|c|c|}
\hline$Z$ & $\begin{array}{c}\text { OL } \\
\text { prediction }\end{array}$ & $\begin{array}{c}\text { Laser } \\
\text { measurement }\end{array}$ & $\begin{array}{c}\text { Nonlaser } \\
\text { measurement }\end{array}$ \\
\hline 31 & & & $840.950(5)^{\mathrm{a}}$ \\
\hline 32 & & & $642.974(5)^{\mathrm{a}}$ \\
\hline 33 & & & $519.437(5)$ \\
\hline 34 & & & $435.1(4)^{b}$ \\
\hline 35 & & & $374.174(5)$ \\
\hline 36 & & & $328.35(20)^{\mathrm{b}}$ \\
\hline 37 & & & $292.490(5)$ \\
\hline 38 & & & $263.71(15)^{\mathrm{b}}$ \\
\hline 39 & 240.2 & $240.11(30)$ & $240.135(15)$ \\
\hline 40 & 220.0 & $220.20(30)$ & $220.290(15)$ \\
\hline 41 & 202.9 & $203.34(30)$ & $203.480(15)$ \\
\hline 42 & 188.3 & $188.95(30)$ & $188.930(15)$ \\
\hline 43 & 175.5 & & \\
\hline 44 & 165.2 & & \\
\hline 45 & 155.3 & & \\
\hline 46 & 146.5 & $146.79(15)$ & \\
\hline 47 & 138.6 & $138.92(15)$ & \\
\hline 48 & 131.4 & $131.66(15)$ & \\
\hline an & $104 \Omega$ & & \\
\hline
\end{tabular}

08-21-06-XRL-JD-10
(Received 11 June 1998)

TABLE II. Comparison of calculated and measured wavelengths of the $4 d^{1} S_{0} \rightarrow 4 p^{1} P_{1}$ transition for Ni-like $\mathrm{Ag}$; wavelengths in angular brackets are predicted. The uncertainties in the last digits are given in parentheses.

\begin{tabular}{cl}
\hline \hline Wavelength $(\AA)$ & Reference \\
\hline $138.92(15)$ & This work \\
143 & {$[13]$} \\
$139.95(15)$ & {$[35]$} \\
$138.9(1)$ & {$[36]$} \\
$\langle 138.6\rangle$ & This work \\
$\langle 139.92\rangle$ & {$[25]$} \\
$\langle 137.76\rangle$ & {$[10]$} \\
\hline \hline
\end{tabular}




\section{In 1998, established LLNL COMET tabletop, laser-driven facility producing pulsed ps duration x-ray laser at 1 shot/4 minutes}

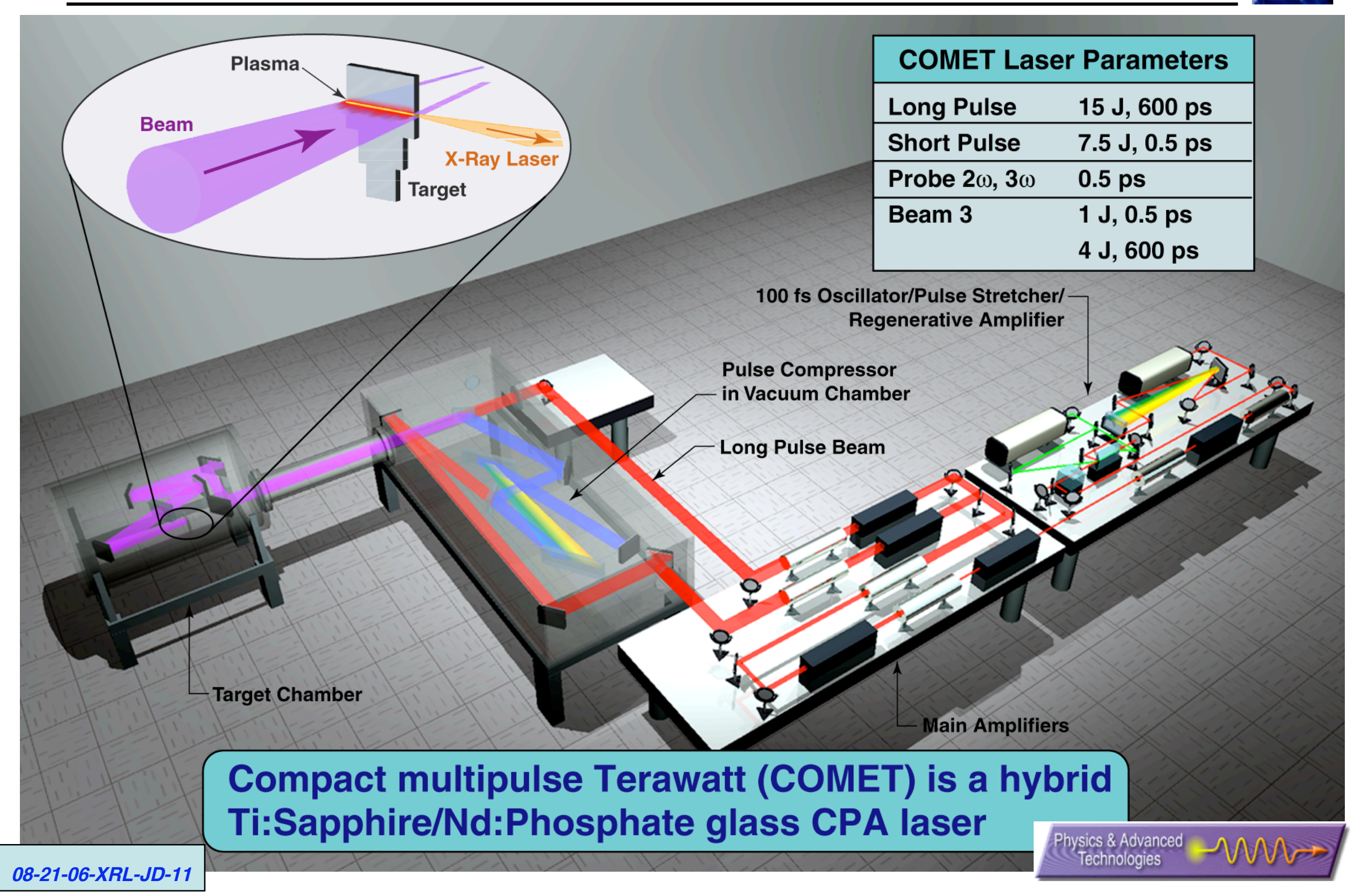




\section{A reflection echelon was used to generate traveling wave line focus in series of steps}

- Streak measurements show effectively no partial traveling wave

- Techniques e.g. tilting compressor gratings ${ }^{1}$ or adding additional grating ${ }^{2,3}$ have been successfully utilized

1 J.-C. Chanteloup et al, X-ray Lasers 1998, IOP Ser. No 159, 653 (1999).

2 J.L. Collier et al, X-ray Lasers 1998, IOP Ser. No 159, 649 (1999).

3 A Klisnick et al, JOSA B 17,1093 (2000)

- Use reflection echelon technique crespo López-Urrutia and Fill, SPIE 2012, 258 (1993).
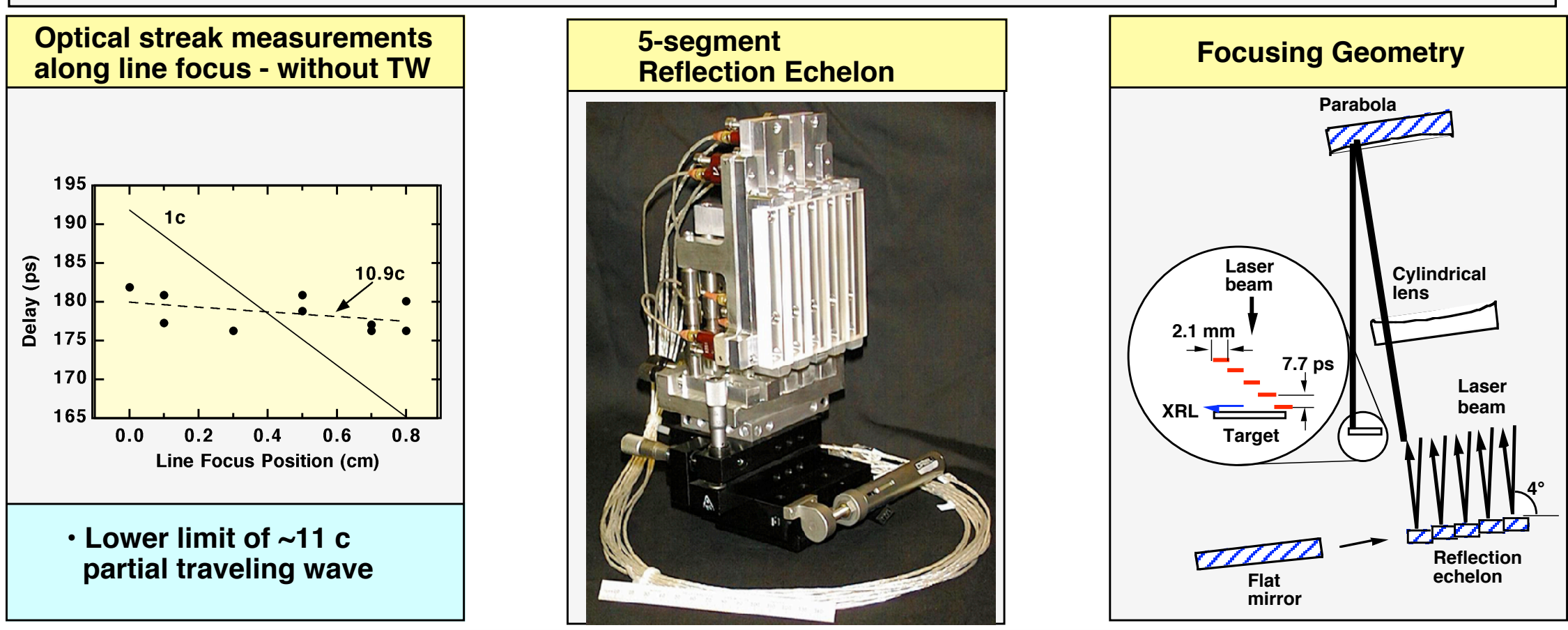
and maintains integrity of 1 ps pulse along line focus 


\section{Strong lasing can be generated on $4 d-4 p$ line of various of $\mathrm{Ni}$-like soft $\mathrm{x}$-ray laser lines}

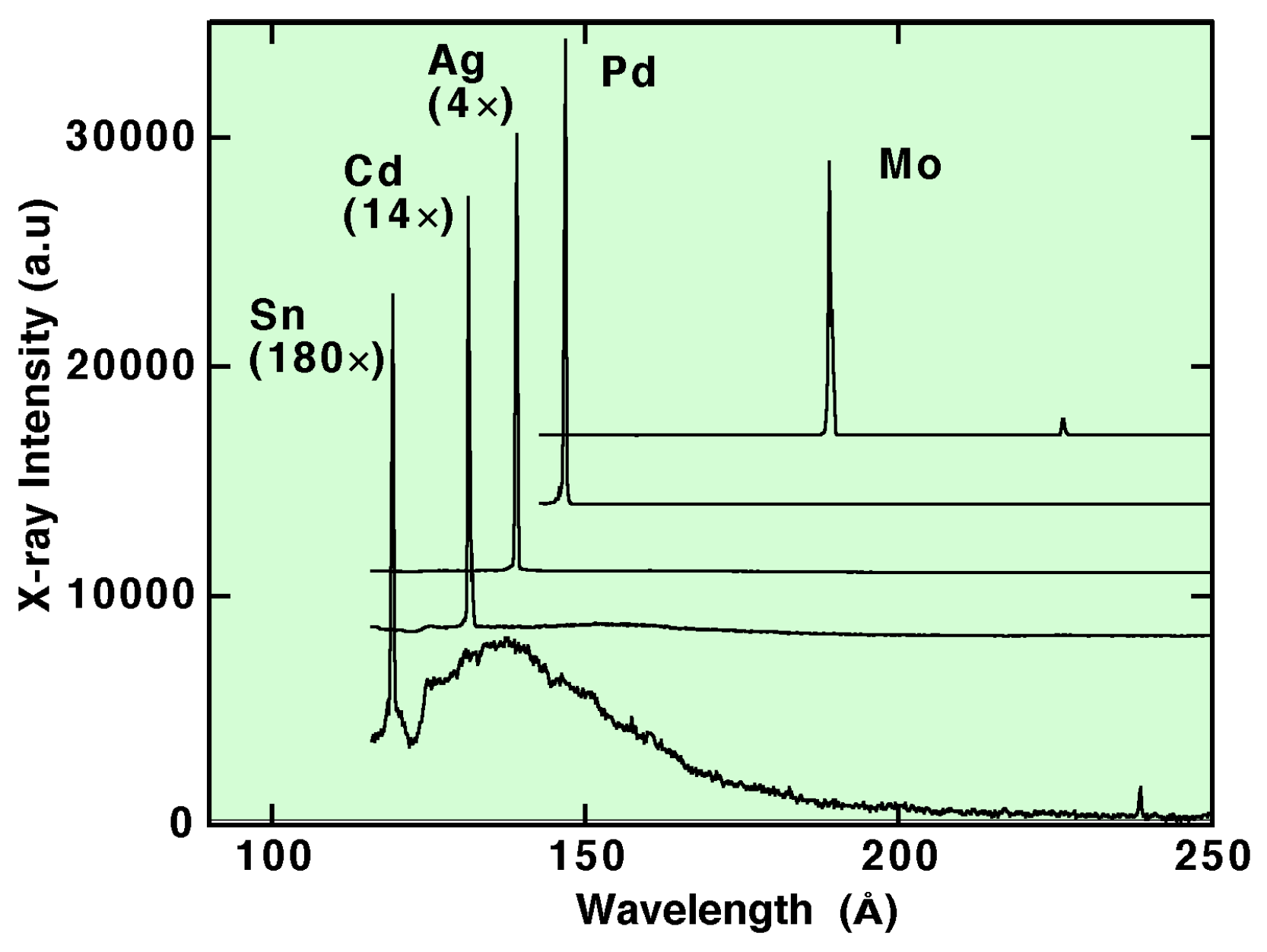

J. Dunn, Y. Li, A.L. Osterheld, J. Nilsen, J.R. Hunter, V.N. Shlyaptsev,

Phys. Rev. Lett $\underline{84}, 4834$ (2000) 


\section{Traveling wave drives $\mathrm{Ni}$-like $\mathrm{Pd}$ at $\mathbf{1 4 . 7} \mathrm{nm}$ into gain saturation regime with $5-7 \mathrm{~J}$ energy in line focus}
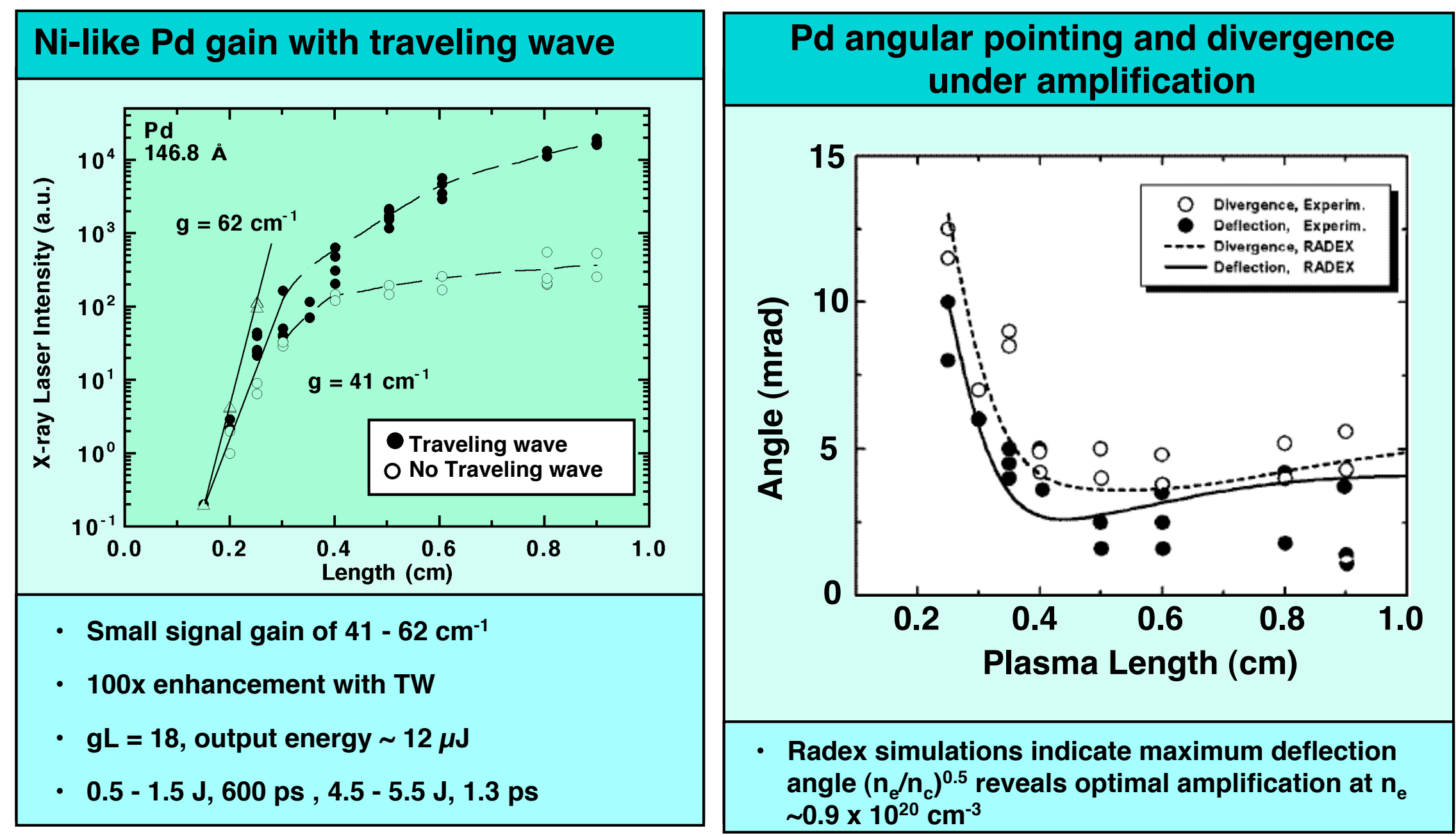

Higher efficiency of Ni-like XRL well matched to small driver

Output still increasing with length - extract more XRL energy 
Motivation for Gas Puff X-ray lasers: Demonstrate efficient lasing using tabletop picosecond laser drivers

Gas puffs are appealing as a laser-driven medium and have a number of substantial differences and advantages to solid targets:

- Can create large plasma medium through choice of nozzle dimensions

- Can control initial gas density using backing pressure, delay

- closer to desired conditions for lasing

- Density gradients within plasma are lower

- better amplification and propagation since refraction of XRL is lower

- No debris generated

- operate at high repetition rates $(>10 \mathrm{~Hz})$

Concerns:

- Very high absorption of XRL beam from cold gas at ends of column

- Laser drive coupling and ionization processes in gas puff plasma are less well understood

H. Fiedorowicz, A. Bartnik 


\section{Picosecond laser driven gas puff x-ray laser setup}
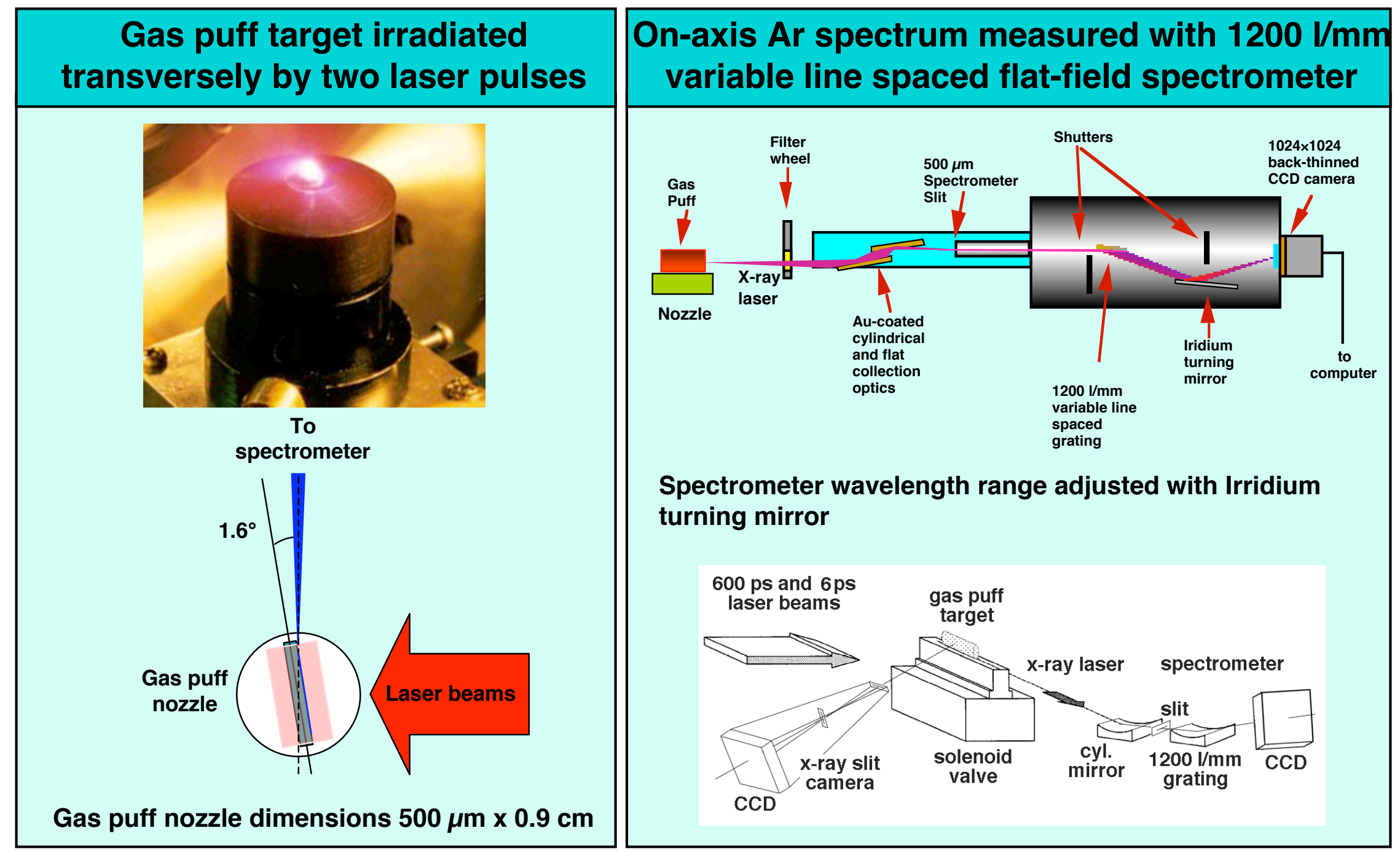


\section{X-ray laser output for $\mathbf{4 5 . 1}$ and $\mathbf{4 6 . 9} \mathrm{nm}$ line determined as a function of plasma column length}
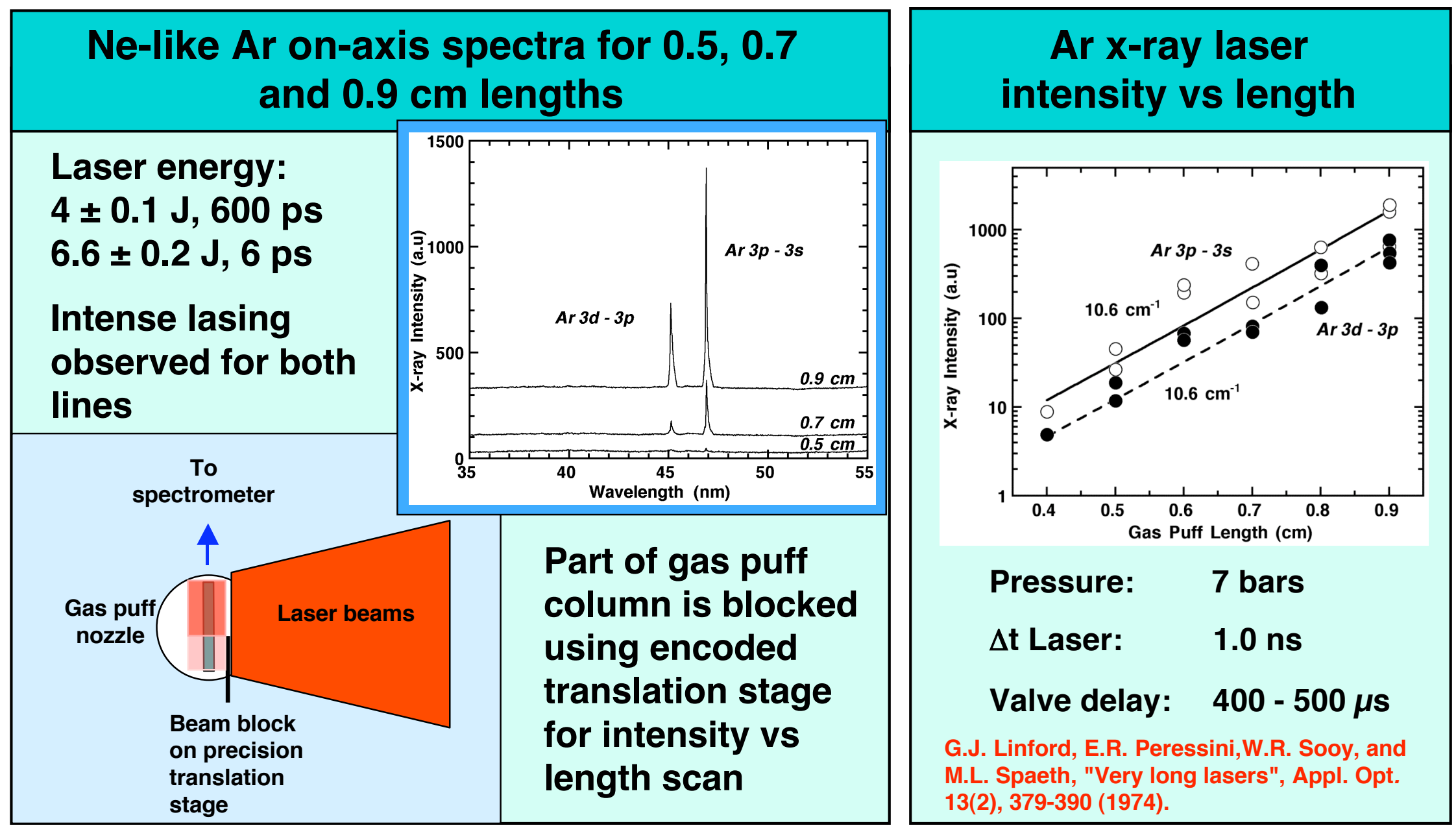

Both lines have similar small signal gain $10.6 \pm 1 \mathrm{~cm}^{-1}$ giving gL product of 9.5 
Characterization of $x$-ray source to improve x-ray laser parameters as a pre-cursor to application development

- Near- and far-field characterization

- Temporal pulse measurements

- Longitudinal coherence - spectral line width measurement

- Spatial coherence

- X-ray laser-based applications

- Interferometry of laser-produced plasmas

- Photo-electron spectroscopy 


\section{Characteristics of $14.7 \mathrm{~nm}$ x-ray laser profile}

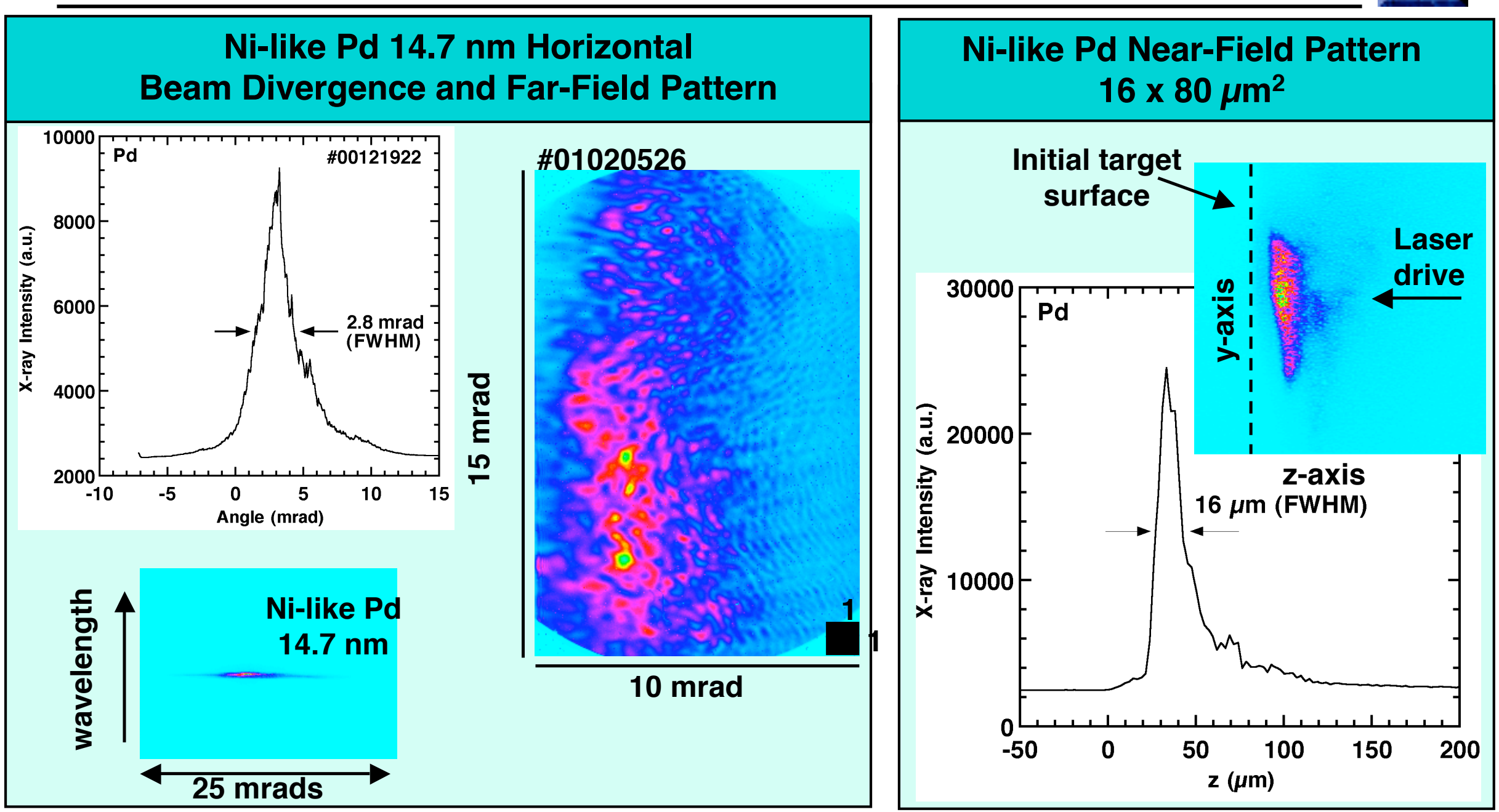

Narrow horizontal beam divergence $2.8 \mathrm{mrad}$ (FWHM) but beam has multi-mode structure - observe some interference in far-field from multiple coherent sources 


\section{0 fs $x$-ray streak camera used to measure temporal duration of $x$-ray laser in 2-D near-field imaging setup}

\section{Experimental Criteria:}

- Spatially resolve $x$-ray laser emission, localize continuum emission

- Minimize instrumental broadening effects (no chirp from spectrometer grating)

- Geometry should be similar to applications

- Control x-ray laser intensity (F1, F2, F3), repeatability, many shots

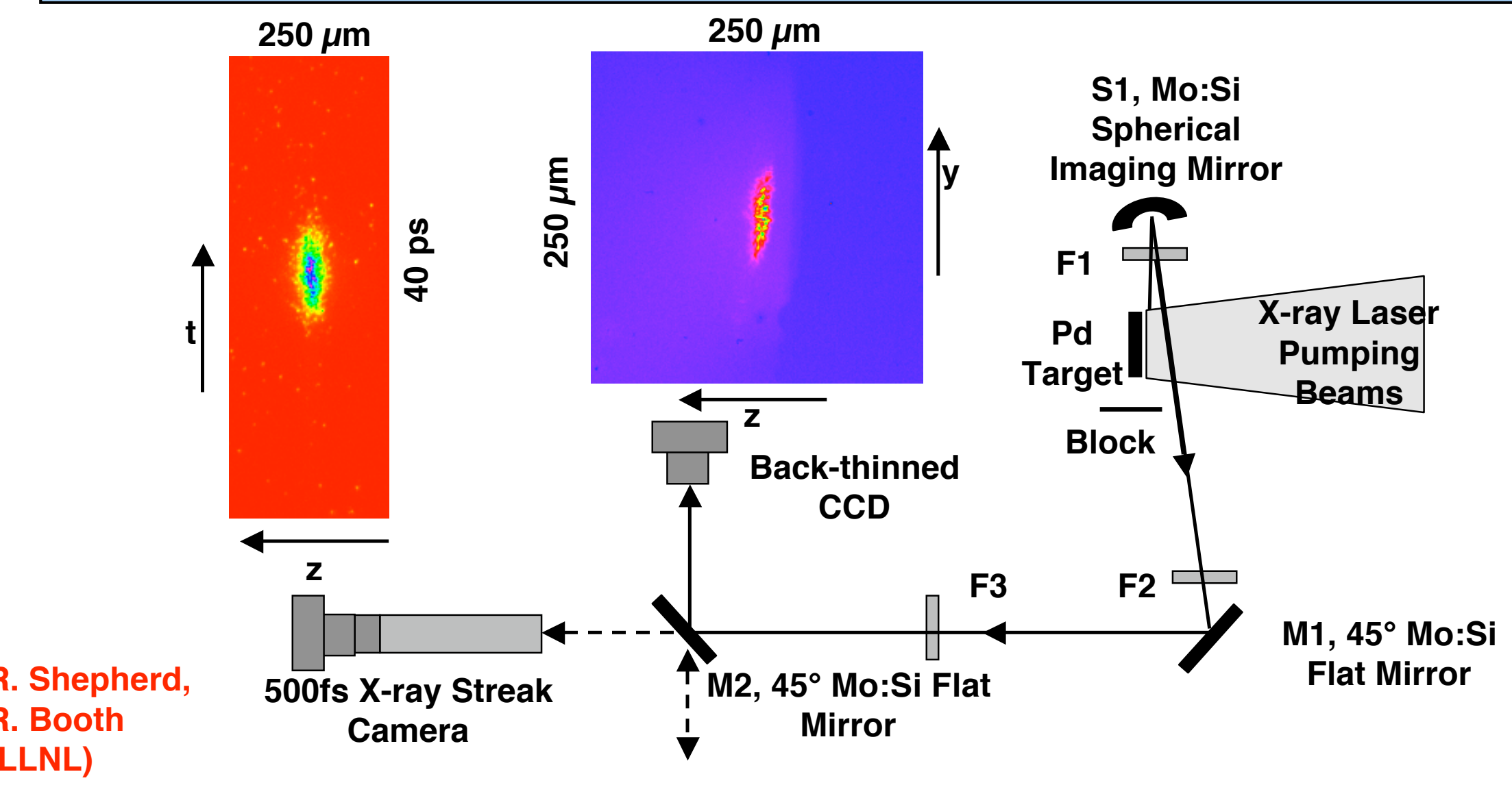

R. Shepherd, R. Booth (LLNL)
$250 \mu \mathrm{m}$ 


\section{$X$-ray laser beam is characterized for interferometry: coherence and fringe visibility with $4-6$ ps duration}

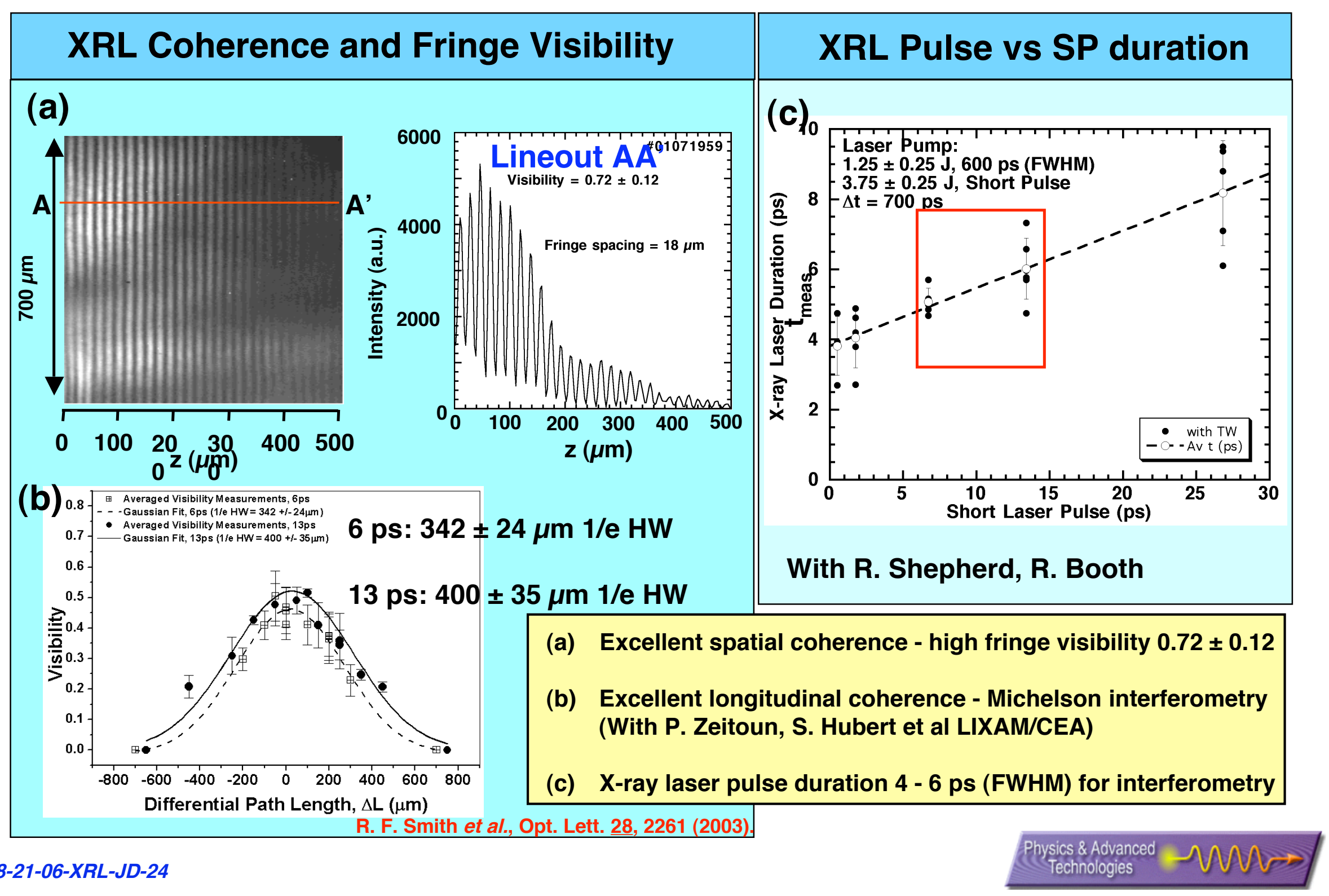




\section{Diffraction Grating X-ray Laser Interferometer Layout:}

Mach-Zehnder configuration for $\mathbf{1 4 . 7} \mathbf{~ n m ~ N i - l i k e ~ P d ~ X - r a y ~ l a s e r ~}$

\section{Detector spatial resolution $\sim 0.5 \mu \mathrm{m}$ Magnification 22x setup Gratings are beam splitters}

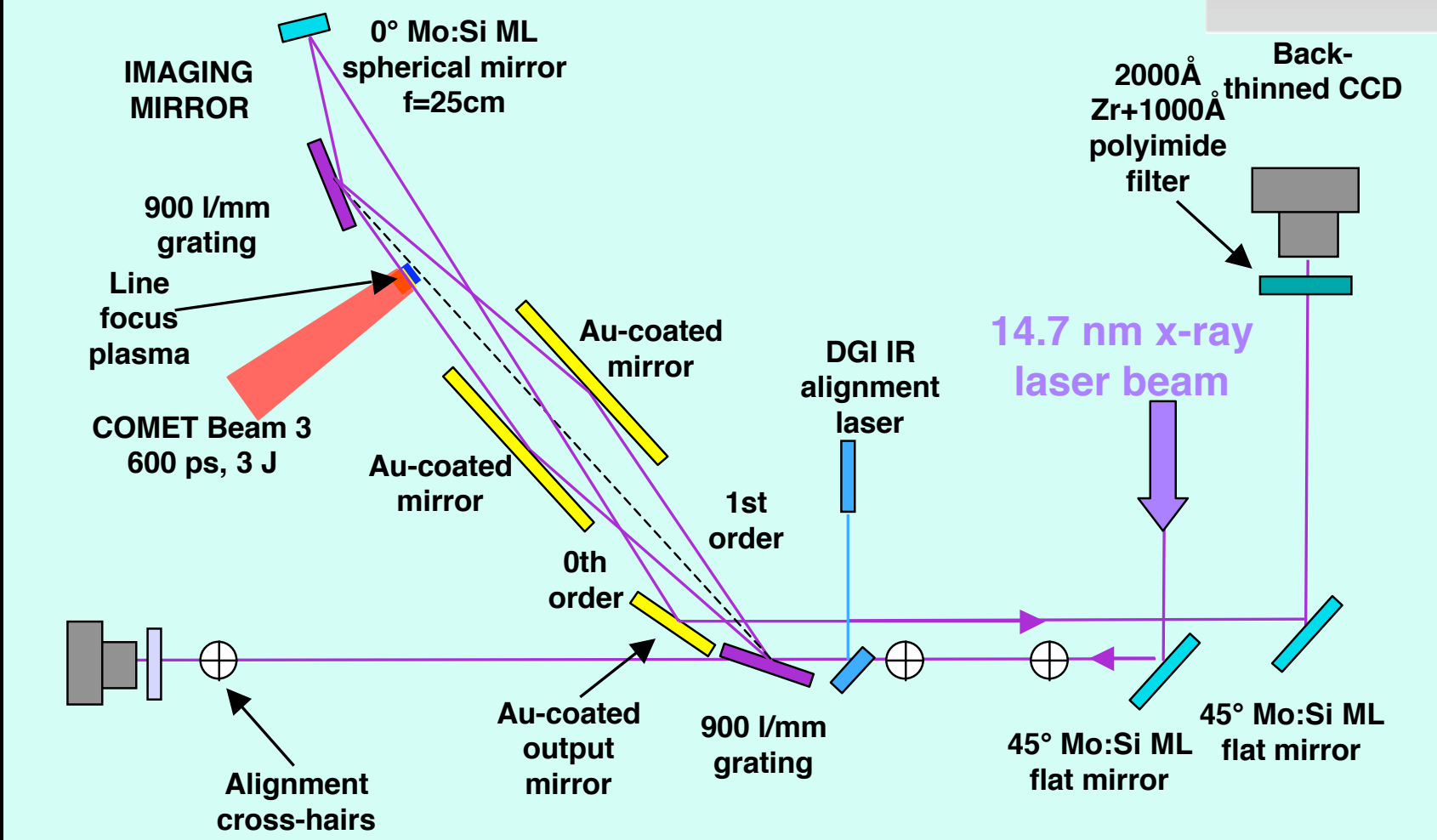

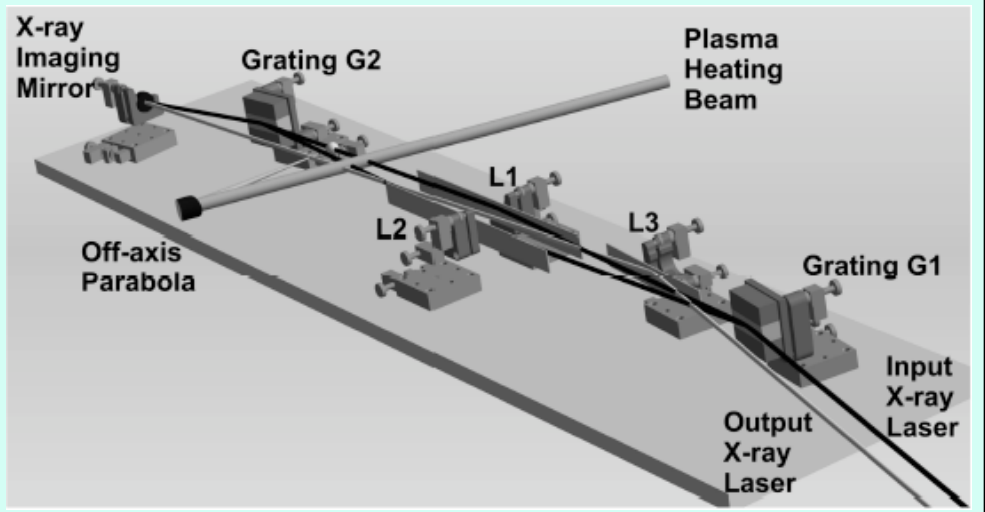
2000A thinned CCD $\mathrm{Zr+1000 \AA}$ olyimide
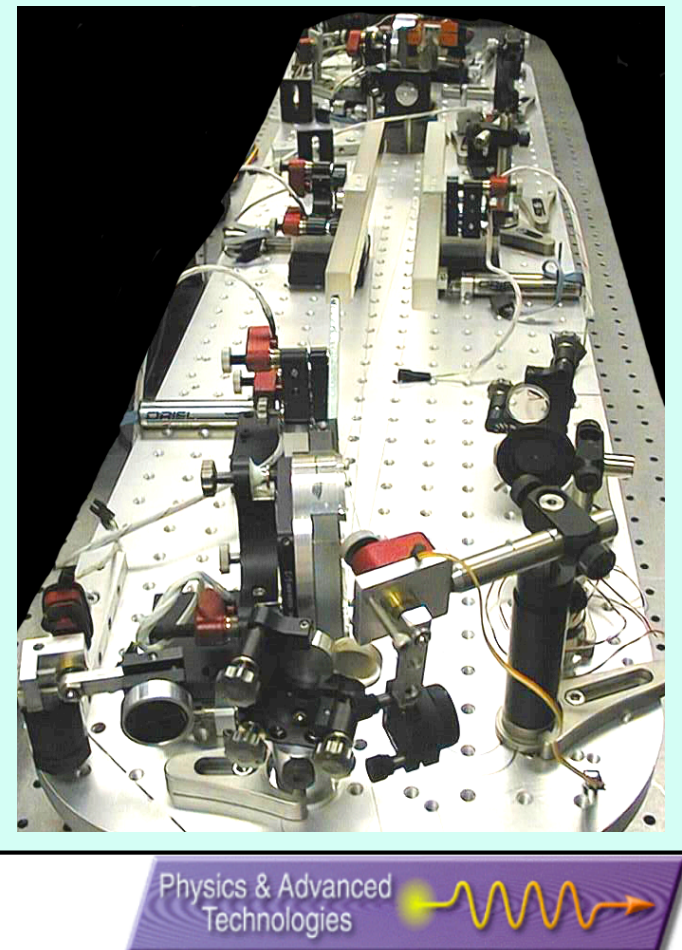


\section{Experiments used to benchmark 2-D LASNEX for high energy density laser-produced plasmas - real tool}

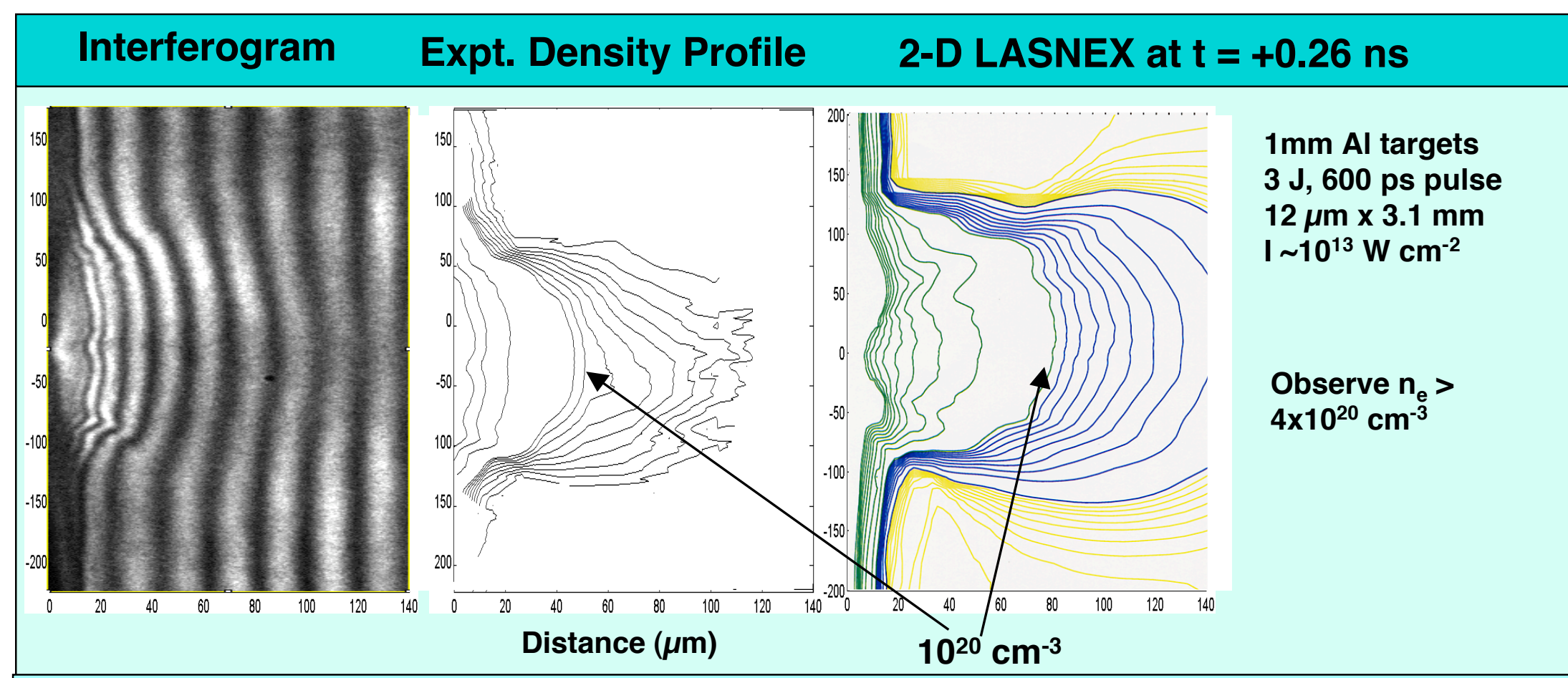

- Small $12 \mu \mathrm{m}$ width results in substantial 2D plasma expansion - reduced on-axis density

- 1D and 1.5D LASNEX simulations do not accurately model plasma conditions

- 2D simulations use experimental focal spot and temporal pulse shape

- Plasma pressure gradients, radiative heating and thermal conduction produces side lobes

Short wavelength, $\sim 1 \mu \mathrm{m}$ spatial and ps time resolution essential 
Experimental interferograms used for comparison with 2-D LASNEX simulations

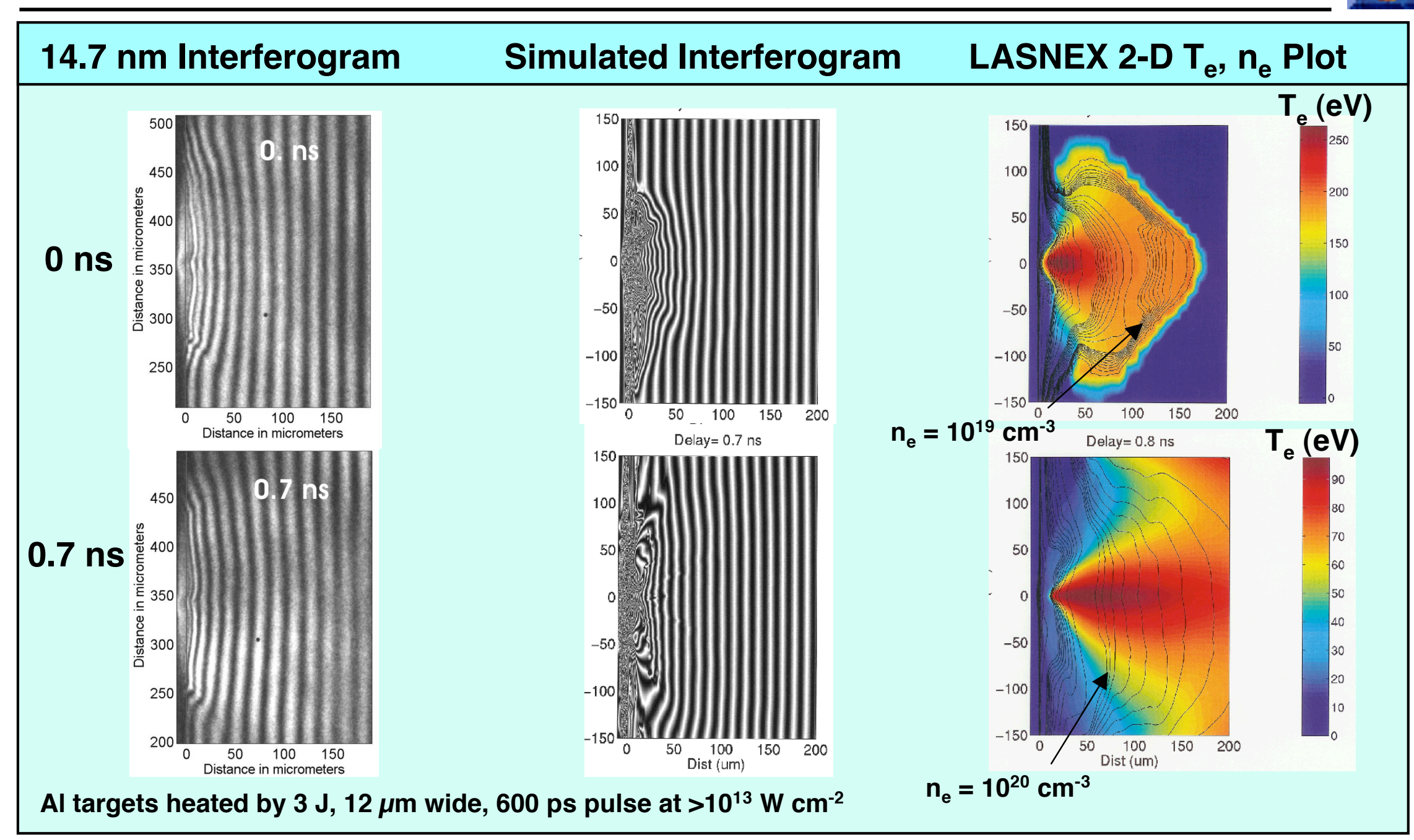

See Poster session for further discussion of LPP phenomena 
Time-of-Flight Photoelectron Spectroscopy requires picosecond pulsed source (84.5 eV x-ray laser photons)

Measure electron kinetic energy by time-of-flight technique

$\mathrm{KE}=\mathrm{hv}-\mathrm{BE}-\phi_{\mathrm{s}}$, Binding energy BE, work function $\phi_{\mathrm{s}}$

- COMET Ni-like Pd X-ray laser photoionizes surface atoms

- Extracted shallow core-level and VB photoelectrons have velocity distribution (kinetic energy distribution $\leq \mathbf{8 4 . 5} \mathrm{eV}$ )

- Time-of-flight (ToF) spectrometer used to energy analyze photoelectrons

- Electrons travel through drift tube detected by micro-channel plate (MCP) and fast digitizer

- Capable of high energy resolution with high throughput

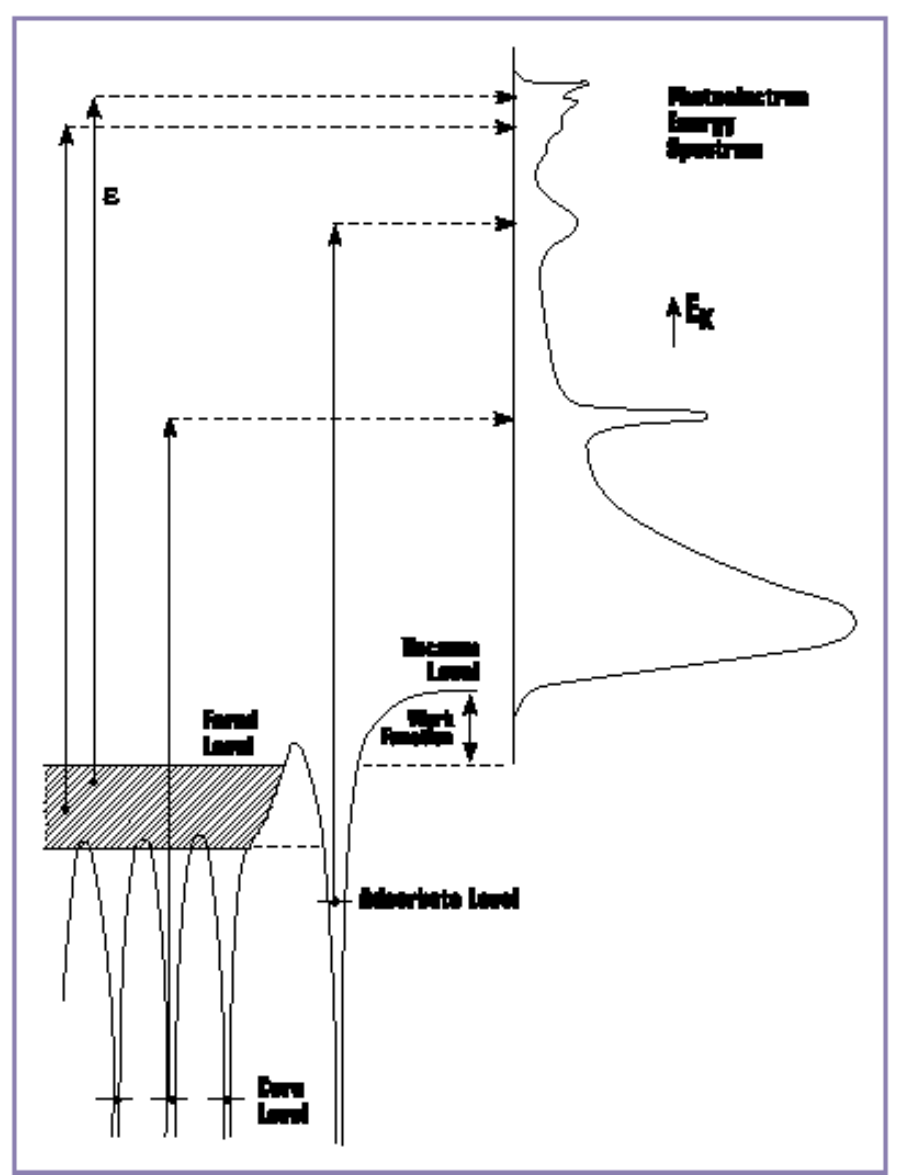




\section{We probe changes in electronic structure during the dynamic processes of melting}

COMET pump-probe experiment with e-ToF PES and soft x-ray radiography

An optical pump melts the material, and the electronic structure is probed after a time $\Delta t$ by $X$-ray laser induced photoelectron spectroscopy

Optical Pump - X-ray laser Probe Experimental Layout
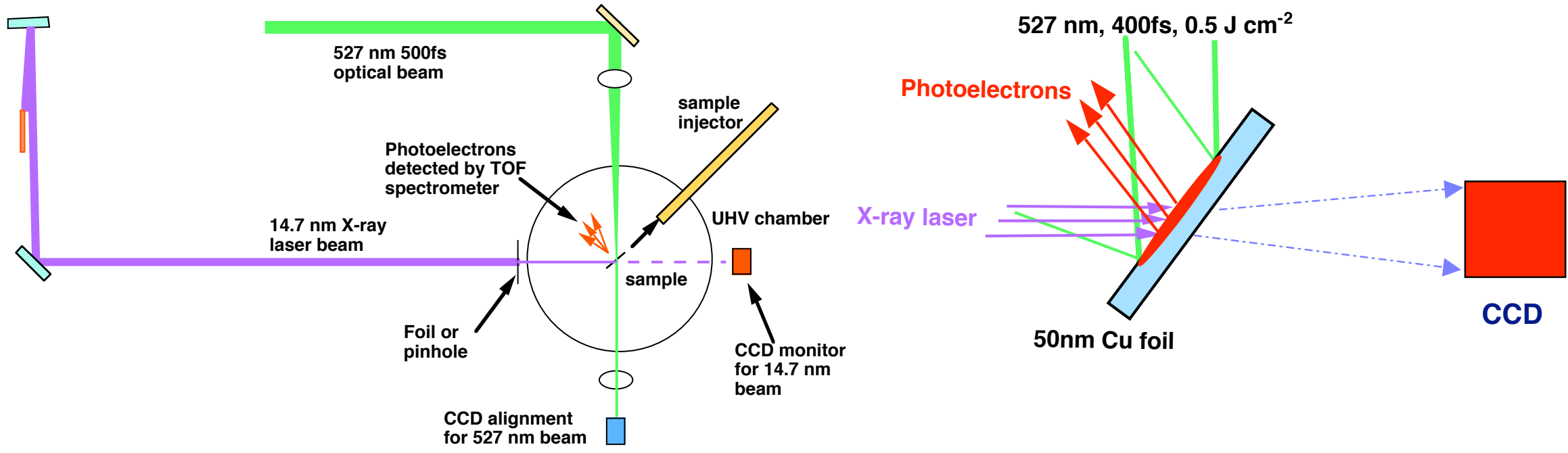

1. Foil or pinhole isolates $x$-ray laser beam line vacuum from UHV chamber

2. Optical beam fluence of $\sim 500 \mathrm{~mJ} / \mathrm{cm}^{2}$ will produce melt - $5-50 \mathrm{~mJ}$ in $1 \mathrm{~mm}$ spot

Dynamic x-ray laser photoelectron spectroscopy of the valence band electronic structure of heated materials has been demonstrated 


\section{Simultaneous measurement of the electronic structure and opacity of $\mathbf{5 0} \mathbf{~ n m ~ C u}$ foils}

- Pump $527 \mathrm{~nm}, 400$ fs laser, $0.1-2.5 \mathrm{~mJ}$ energy in $500 \times 700 \mu \mathrm{m}^{2}$ (FWHM) spot.

- Heating with $0.07-1.8 \times 10^{12} \mathrm{~W} \mathrm{~cm}^{-2}$ intensity

- $\mathrm{Cu} d$ band emission evident in valence band

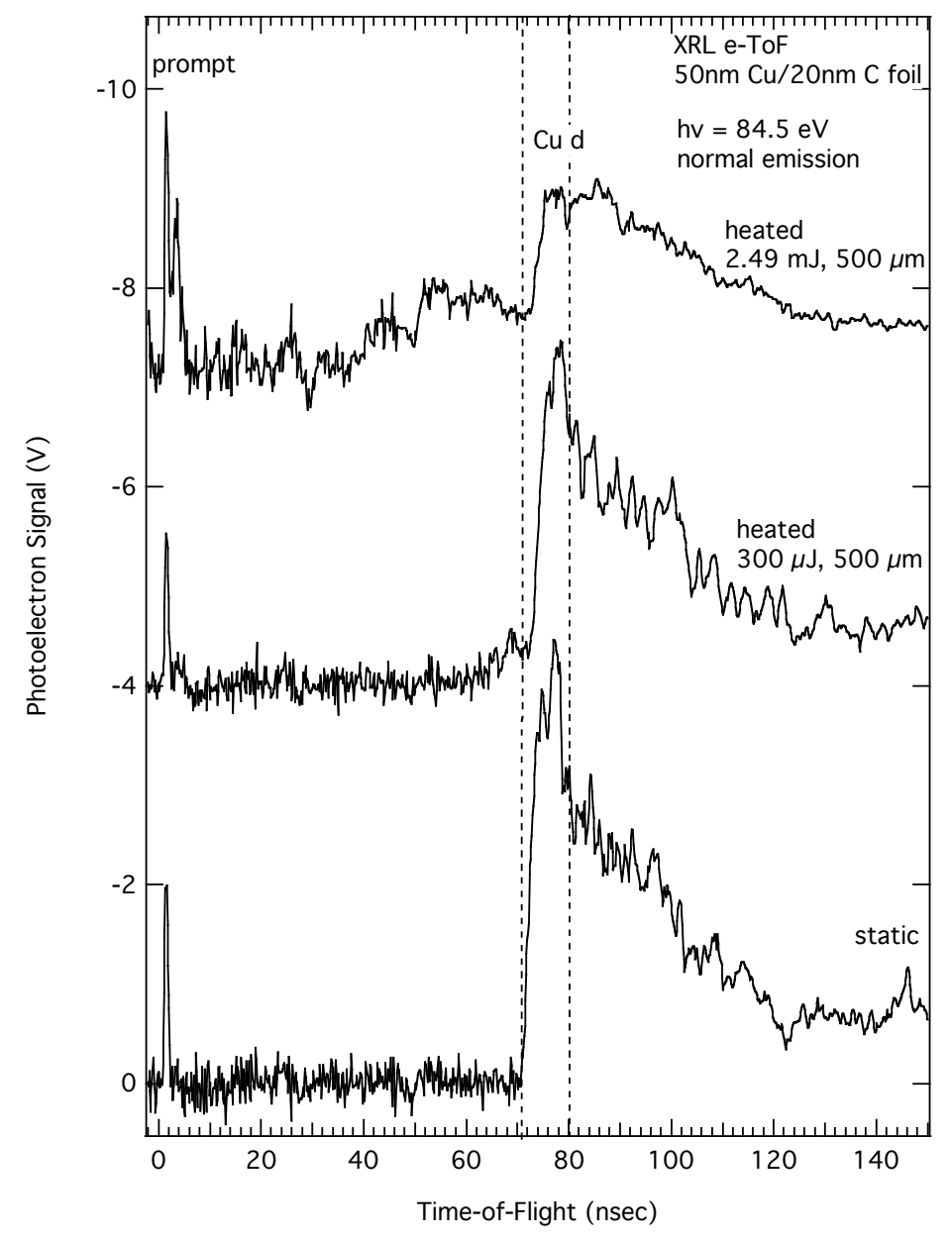

Single-shot e-ToF normal emission spectra of static and laser heated ultrathin $\mathrm{Cu}$ foil

decreasing $\mathrm{Cu} 3 d$ peak intensity due to depopulation of the $d$-band as the electron temperature $T_{e}$ increases

creates vacancies in the $\mathrm{CB}$ - interband absorption below the edge $3 d-4 p$ transitions

Cu $3 d$ peak shifts towards lower kinetic energy (higher binding energy) - band is 'sinking'.

no broadening of the $\mathrm{Cu} 3 d$ upon heating nonequilibrium distribution of occupied states 
Other x-ray laser schemes proposed but not yet observed: Energy level diagram for Nd-like $U \mathbf{5 f}-\mathbf{5 d}$ transition at $6.7 \mathrm{~nm}$

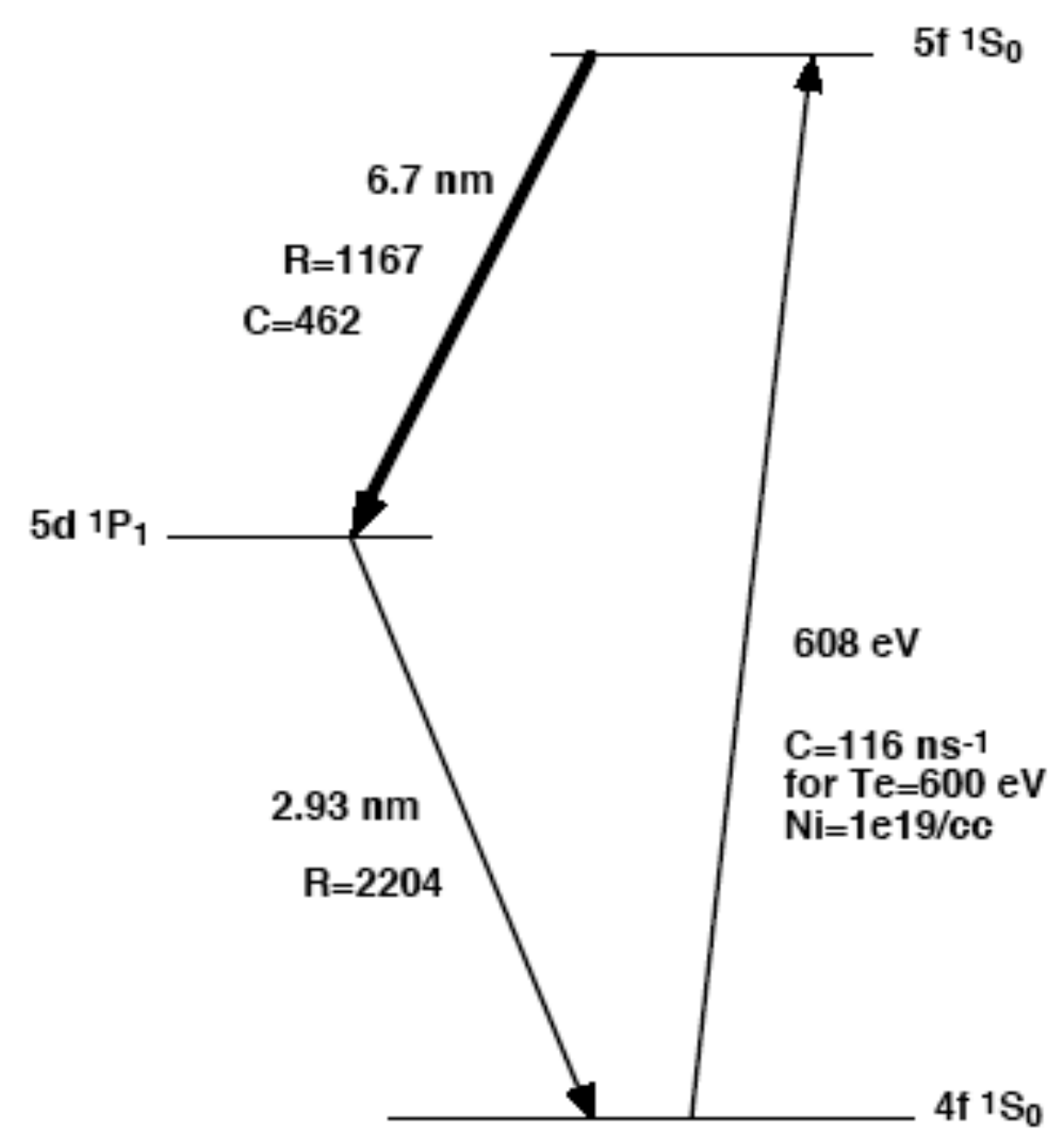

Joe Nilsen, LLNL

Nd-like U (IP=1301 eV) 
Overview and Summary:

Give highlights of 10 years (1997 - 2006) of research in Tabletop X-ray Lasers at LLNL

- Initial motivation and background

- Development of laser system

- First Ne-like and Ni-like x-ray laser results

- Generation of saturated output

- Characterization of $x$-ray laser source

- Description of applications at COMET

- Future directions and comments 